\title{
Biosynthesis and function of GPI proteins in the yeast Saccharomyces cerevisiae
}

\author{
Martine Pittet, Andreas Conzelmann* \\ Department of Medicine, Division of Biochemistry, Chemin du Musée 5, CH-1700 Fribourg, Switzerland
}

\begin{abstract}
Like most other eukaryotes, Saccharomyces cerevisiae harbors a GPI anchoring machinery and uses it to attach proteins to membranes. While a few GPI proteins reside permanently at the plasma membrane, a majority of them gets further processed and is integrated into the cell wall by a covalent attachment to cell wall glucans. The GPI biosynthetic pathway is necessary for growth and survival of yeast cells. The GPI lipids are synthesized in the ER and added onto proteins by a pathway comprising 12 steps, carried out by 23 gene products, 19 of which are essential. Some of the estimated $60 \mathrm{GPI}$ proteins predicted from the genome sequence serve enzymatic functions required for the biosynthesis and the continuous shape adaptations of the cell wall, others seem to be structural elements of the cell wall and yet others mediate cell adhesion. Because of its genetic tractability S. cerevisiae is an attractive model organism not only for studying GPI biosynthesis in general, but equally for investigating the intracellular transport of GPI proteins and the peculiar role of GPI anchoring in the elaboration of fungal cell walls.
\end{abstract}

Keywords: Glycosylphosphatidylinositol; Saccharomyces cerevisiae; Biosynthesis; Cell wall; Ceramide; Lipid remodeling

\section{Introduction}

Glycosylphosphatidylinositol (GPI) anchors are structurally complex glycophospholipids, which are added posttranslationally to the C-terminal end of secretory proteins after they have been translocated into the ER. GPI anchoring is utilized by most eukaryotes to express proteins at the cell surface. The structural components of some GPI anchors began to be identified in the 1980s and complete structures for the variant surface glycoproteins of Trypanosoma brucei and the mammalian Thy-1 glycoprotein had been worked out by Mike Ferguson, Steve Homans and their coworkers in 1988 [1,2]. This pioneering structural work opened the door to studies concerning the biosynthesis of GPI lipids and their attachment to proteins as well as the identification

Abbreviations: aa, amino acids; CPY, carboxypeptidase Y; CWP, cell wall protein; Dol-P-Man, dolicholphosphomannose; EtN-P, phosphorylethanolamine; GlcNAc, N-Acetyl-Glucosamine; $\mathrm{GlcNH}_{2}, \mathrm{GlcN}$, Glucosamine; GPI, glycosylphosphatidylinositol; Man, mannose; PE, phosphatidylethanolamine; PI, phosphatidylinositol; PI-PLC, PI-specific phospholipase C; PMP, plasma membrane protein; TM, transmembrane domain

* Corresponding author. Tel.: +41 26300 8630; fax: +41 263009735 .

E-mail address: andreas.conzelmann@unifr.ch (A. Conzelmann). of the genes involved in these processes. Presently, after 20 years of intensive work, genes required for the addition of about everyone of the different structural elements of the GPI anchor have been identified, but new subunits and regulatory elements of the identified enzymes continue to be discovered.

Precursors of GPI anchored proteins have a classical signal sequence for import into the ER at their N-terminus and a GPI anchoring signal at their $\mathrm{C}$-terminus; the $\mathrm{C}$-terminal signal is necessary and sufficient to direct GPI addition [3]. The C-terminal GPI anchoring signal is recognized and removed by a GPI transamidase, which replaces it by the preformed GPI. GPI anchoring signals are composed of a C-terminal hydrophobic domain, which is separated by a short hydrophilic spacer from the cleavage/attachment site ( $\omega$ site) [4-6]. While several amino acids can serve as anchor attachment sites in other organisms (Ser, Asp, Ala, Asn, Gly, Cys), only Asn and Gly have been found so far in yeast. Nevertheless, the yeast transamidase also can add very efficiently to Ser, and with lower efficiency to Asp, Ala, and Cys [6]. A bioinformatics predictor specially designed for fungal genomes has recently become available and allows to predict GPI proteins and $\omega$ sites from protein sequence data more accurately than using the analogous predictors optimized for animal or plant 
sequences (http://mendel.imp.univie.ac.at/gpi/fungi_server.html) [7].

Fig. 1A shows the average structure of the yeast GPI anchor as elaborated from the total pool of GPI anchors extracted from yeast cells without the prior purification of any particular GPI protein $[8,9]$. The structure of the GPI core linking the protein to the lipid moiety is the same as in other organisms. Indeed, this core structure is very conserved among all eukaryotes, and the same is true for the enzymes that elaborate that structure: Almost all the genes identified as being essential for a given enzymatic step in mammalian or yeast cells have found their homologues in other eukaryotes. Amazingly, even certain side chains such as the forth mannose (Man4) or the phosphorylethanolamine (EtN-P) side chains added on Man1 and Man2 (Fig. 1A) are present both, in man and in yeast and thus have been conserved across long evolutionary distances. Thus, the GPI biosynthesis pathway is a very ancient and highly conserved pathway.

Excellent recent reviews summarize current knowledge about the biosynthesis of GPI anchors and the enzymes that are necessary for their elaboration [10-15].

The present review focuses on new data that emerged recently and have extended our understanding of the biosynthesis and role of GPI anchored protein in S. cerevisiae.

\section{General properties of GPI proteins of yeast}

All known GPI proteins of yeast seem to end up either at the plasma membrane or in the cell wall. A certain number of cell wall proteins (CWPs) of $S$. cerevisiae can be extracted from the
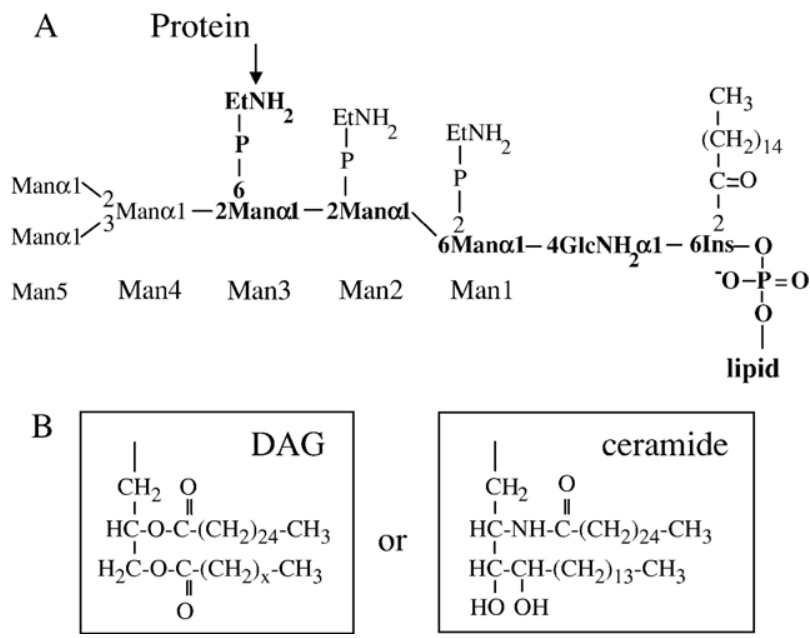

Fig. 1. Structure of GPI anchors of yeast. (A) The average structure of the yeast GPI anchor as elaborated from the total pool of GPI anchors [8,9]. The conserved carbohydrate core structure is in bold characters. The most mature GPI lipid (CP2) accumulating in GPI transamidase mutants contains 4 mannoses (Man1 to Man 4) and phosphorylethanolamine $\left(\mathrm{EtNH}_{2}-\mathrm{P}\right)$ substituents on Man1, Man2 and Man3. A 5th mannose (Man5) can be added to GPI proteins while they transit through the Golgi apparatus, whereby Man5 is added either in $\alpha 1-2$ or in $\alpha 1-3$ linkage [8,111]. Although present on $\mathrm{CP} 2$, it is not certain that the $\mathrm{EtNH}_{2}-\mathrm{P}$ on Man2 is present on GPI anchors of proteins [9]. The palmitic acid on the inositol (Ins) is present on all but the earliest free GPI lipids but it is removed as soon as the GPI lipid is attached to a protein. (B) The two alternative lipid moieties, diacylglycerol (DAG) or ceramide are found on mature GPI proteins. In both anchor lipids the $\mathrm{C} 26$ fatty acid can be $\alpha$-hydroxylated [8]. x probably is 14 or 16 . glucan mesh simply by boiling in SDS cells in the presence of a reducing agent to break disulfide bridges. A larger part of cell wall proteins however is covalently linked to the insoluble glucan meshwork. Of those, the majority are first made as GPI anchored proteins, which at a certain maturation stage loose the lipid moiety of the GPI anchor and get attached through the remaining mannose residues of the anchor to $\beta 1,6$-glucans. If these GPI-CWPs are expressed without the C-terminal GPI attachment signal, they are not attached to the glucan mesh and in many cases are secreted [16-18]. Similarly, certain GPI proteins are secreted when the amount of $\beta 1,6$ glucan is greatly diminished [19-21]. GPI-CWPs can be selectively removed from the cell walls by treatment with endo- $\beta 1,6$-endoglucanase or hydrofluoric acid (HF) [22]. A minor subpopulation of cell wall proteins are not GPI proteins but are nevertheless attached to glucans through a covalent, alkali-sensitive linkage; these proteins have been named ASL-CWPs [23]. Recent reviews summarize current knowledge about the yeast cell wall architecture [23-28].

Comprehensive lists of GPI proteins have been compiled by in silico analysis of the yeast genome [7,29-31] but only for a minority of them the existence of a GPI anchor has been established biochemically. Biochemical evidence can be obtained through indirect methods, e.g., through the demonstration of a loss of hydrophobicity upon treatment with PI-specific phospholipase C (PI-PLC), through metabolic labeling with anchor components such as $\left[{ }^{3} \mathrm{H}\right]$ inositol, by the loss of surface localization upon site directed mutation of a putative $\omega$ site, or by the demonstration of a covalent, alkali-resistant, glucanase-sensitive association with the cell wall, for which the addition of a GPI anchor is a prerequisite. A more direct demonstration of GPI anchoring is obtained through purification of GPI proteins and the analysis of their C-terminal end by chemical and physical methods, e.g., mass spectrometric analysis [32].

\section{Biosynthesis of GPI lipids in yeast}

\subsection{Technical aspects}

Contrary to other systems, metabolic labeling of yeast cells with components of the GPI anchor such as mannose or inositol does not allow to detect any free GPI lipids, whereas inositollabeled GPI proteins can readily be detected. This suggests that the steady state level of free GPI lipids is very low. However, the main reason for the failure to detect free GPI lipids after metabolic labeling may be the fact that the GPI lipids are not made in excess of what is needed for GPI anchoring and that yeast does not contain any free GPIs in its cell membranes as is the case in other organisms. The main pathway generates CP2, which contains 4 mannoses and 3 EtN-P's as depicted in Fig. 2. CP2 is the largest and most polar GPI precursor lipid of yeast and is supposed to be attached to proteins. It is unclear whether CP2 is the only GPI lipid that gets attached to proteins in as much as other GPI lipids lacking EtN-P side chains on Man1 or Man2 equally accumulate, when the transamidase ceases to work and since there presently is no biochemical prove that yeast GPI protein anchors carry an EtN-P on Man2 [9]. 


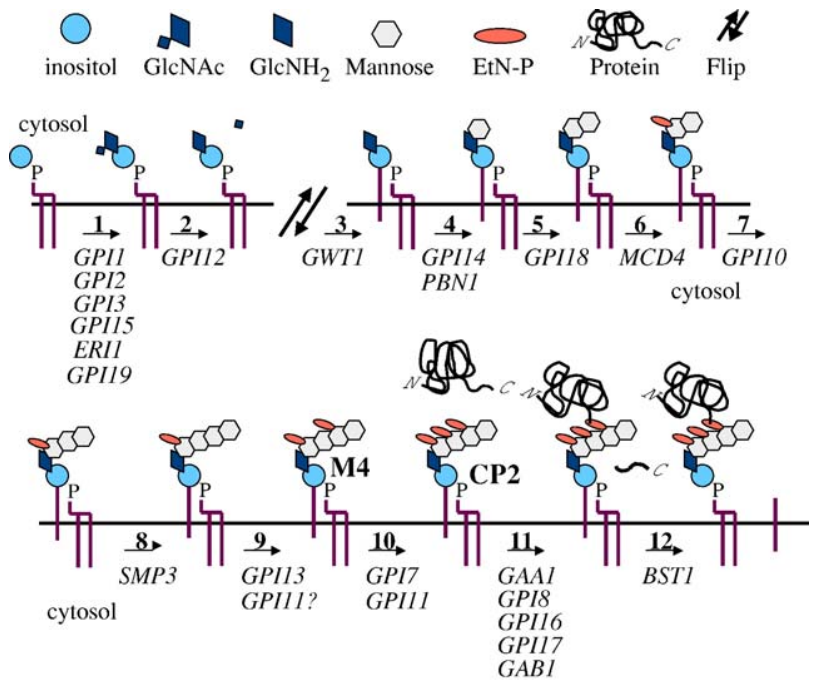

Fig. 2. The main pathway of GPI biosynthesis in yeast. Since no GPI intermediates are detectable in wild type cells, a likely pathway is proposed based on structures of GPIs accumulating in well-characterized gpi mutants $[62,68,71,72,166]$. Biosynthetic steps are numbered in accordance with the description in Table 1. CP2 is the most polar lipid accumulating in gpi8 mutants. M4 is also transferred to GPI proteins, since GPI7 is non-essential [71]. All genes in the pathway encode integral membrane proteins having at least one and in most cases multiple membrane spanning domains.

3.2. GPI lipids are built by the stepwise addition of sugars and phosphorylethanolamine to phosphatidylinositol

The genes encoding the different enzymes involved in the biosynthesis of GPI anchors have been cloned mostly by the complementation of mammalian or yeast mutants. Non-anchored GPI proteins do not reach the cell surface and selecting for cell lines lacking GPI proteins at their surface has allowed to isolate PIG and gpi mutants in mammalian cell lines and yeast, respectively, which are defective in one of the biosynthetic enzymes listed in Table 1. The focus of this review will be on those steps, for which new data have been reported or in which the yeast machinery shows different characteristics than the mammalian one. Although the homology between yeast an mammalian genes is usually low, it tends to be higher for those proteins, which have a catalytic activity (Table 1). In many cases heterologous expression experiments have shown that yeast genes produce functional proteins in mammalian cells and vice versa. The numbering of steps in Table 1 is somewhat tentative and indicates the most likely sequence of enzymatic reactions based on the structure of the GPI intermediates that accumulate in PIG or gpi mutants. The various steps are also visualized in Fig. 2.

\subsubsection{Step 1: PI-GlcNAc-transferase}

The committed step of GPI biosynthesis is the addition of GlcNAc to PI. This transfer reaction occurs at the cytosolic surface of the ER and is critically dependent on Gpi3p, Gpilp, Gpi2p, and Gpi15p and Gpi19p, which together form a multisubunit enzyme complex in the ER [33-35]. For some of them, the corresponding genes have first been cloned in the mammalian system by the group of Taroh Kinoshita, and the interactions of the various partners has been elaborated mainly in this system. However the strict conservation of all subunits in yeast and limited biochemical analysis suggest that the same multisubunit complex is operating in yeast [35]. Gpi3p contains a glycosyltransferase motif that is utilized by many glycosyltransferases of widely different specificity (Pfam PF00534), as well as a further motif, that is only shared amongst enzymes transferring GlcNAc to PI (Pfam PF08288). Gpi3p must be the catalytic subunit since it binds UDP-GlcNAc, and it does so without the help of other subunits [36]. Human GPI1 (PIG-Q) was shown to stabilize other components of the complex and to tie PIG-C to PIG-A and PIG H. Deletion of human GPI1 did however not totally abolish GPI anchoring of proteins [37]. A similar situation prevails in yeast: Gpilp is not absolutely required and the low amount of GPIs made in gpil $\Delta$ mutants is sufficient to keep cells viable at $24{ }^{\circ} \mathrm{C}$, but gpil $\Delta$ mutants are not viable at $37^{\circ} \mathrm{C}$. The mammalian enzyme complex also binds to and is stimulated by DPM2, a subunit of the mammalian Dol-P-Man synthase complex [38]. In contrast, the Dol-P-Man synthase of yeast shows a slightly different structure and consists of a single subunit, Dpm1p, and there is no homologue of DPM2 in yeast [39]. Finally, Erilp has recently been identified as a further component of the yeast PIGlcNAc-transferase, which can be coprecipitated with Gpi2p [40]. ERII, as GPII, is required for cell growth at $37^{\circ} \mathrm{C}$ but not at $24{ }^{\circ} \mathrm{C}$. ERII encodes a 68 amino acid long, very hydrophobic miniprotein that seems to be genuinely required for GPI anchor biosynthesis as its depletion leads to the accumulation of an unanchored form of Gas $1 p$, and because microsomes isolated from an eril $\Delta$ mutant exhibit defects in the transfer of GlcNAc to an acceptor PI [40]. The mammalian ERI1 homologue PIG-Y has been cloned recently [41]. It has $22 \%$ sequence identity with ERI1 and exhibits a similar hydropathy profile as Erilp. PIG-Y binds to PIG-A, but no other component of the PI-GlcNActransferase complex. This suggests that the interaction of yeast Eri1p with Gpi2p may also be mediated by Gpi3p. The other six subunits of the mammalian PI-GlcNAc-transferase form a complex even in the absence of PIG-Y [41]. By analogy, a hydrophobic, very short (36 amino acids (aa) long) protein named Ost4p is also present in the OST complex transferring oligosaccharides onto Asn residues for $\mathrm{N}$-glycosylation. In contrast to Erilp, Ost4p is required to stabilize the OST complex [42].

\subsubsection{Step 3: inositol acylation}

O-palmitoylation of inositol in GPI structures was first noted in studies on the GPI anchor of human erythrocyte acetylcholinesterase and was demonstrated to be the cause of the resistance of GPI proteins or lipids to PI-PLC $[43,44]$. Subsequent studies in many organisms showed that GPI lipids are usually acylated on the inositol while in protein anchors in general the inositol is not acylated [45]. Persistence of an acyl group on inositol in the protein-bound GPI anchors was however observed in human erythrocyte acetylcholinesterase, in GPI proteins of L929 fibroblasts [46], as well as in the myristoylated GPI anchors of Plasmodium falciparum [47]. This persistence is somewhat surprising since it has been shown that GPI proteins are not efficiently transported from the ER to the Golgi, if they are not deacylated [48]. The acyl is attached to C2 of the 
Table 1

Genes known to be necessary for the biosynthesis of GPI anchors in yeast

\begin{tabular}{|c|c|c|c|}
\hline & $\begin{array}{l}\text { Yeast gene names, (human homologue, \% } \\
\text { identity with yeast gene) }\end{array}$ & Specific function/Remarks & $\begin{array}{l}\text { Number of aa, codon bias, number of } \\
\text { potential TM (human homolog) }\end{array}$ \\
\hline \multirow[t]{6}{*}{$\begin{array}{l}\text { Step 1: N-Acetyl-Glucosamine- } \\
\text { transferase PI-GlcNAc- } \mathrm{T}^{\mathrm{a}}\end{array}$} & GPI3 YPL175w SPT14 (PIG-A 46\%) & $\begin{array}{l}\text { Catalytic subunit of the enzyme } \\
\text { complex. Binds UDP-GlcNAc }\end{array}$ & 452aa 0.026, 0 TM; (484aa, $1 \mathrm{TM})$ \\
\hline & GPI2 YPL076w (PIG-C 21\%) & $\begin{array}{l}\text { PIG-C binds through PIG-Q to PIG-A } \\
\text { and PIG-H. Gpi2p binds Gpi19p }\end{array}$ & 280aа, 0.11, 6 TM (292aa, 8 TM) \\
\hline & GPII 5 YNL038w (PIG-H 24\%) & $\begin{array}{l}\text { PIG-H makes tight, direct } \\
\text { interaction with PIG-A }\end{array}$ & 229 aa, $-0.02,2$ TM; (188aa, 2 TM) \\
\hline & GPII YGR216c (PIG-Q 22\%) & $\begin{array}{l}\text { PIG-Q links PIG-A/PIG-H to PIG-C, } \\
\text { stabilizes PIG-H and PIG-C }[37,167]\end{array}$ & 609aa, 0.006, 6 TM; (581aa, $6 \mathrm{TM})$ \\
\hline & GPII 9 YDR437w (PIG-P 24\%) & PIG-P binds PIG-A and PIG-Q. & 140aa, CB 0.0142 TM; (134aa, 2 TM) \\
\hline & ERII YPL096c-A (PIG-Y 22\%) & $\begin{array}{l}\text { Interacts with Ras } 2 p \text { and Gpi } 2 p \text { for } \\
\text { regulation of the GPI pathway }\end{array}$ & 68aa, 0.042, 2 TM; (71aa, 2 TM) \\
\hline $\begin{array}{l}\text { Step 2: GlcNAc-PI de-N- } \\
\text { acetylase }\end{array}$ & GPII2 YMR281w (PIG-L 32\%) & $\begin{array}{l}\text { May interact with PIG-M in T. brucei } \\
\text { and L. major but not in mammals }\end{array}$ & 304aa, 0.091, 1 TM; (252aa, 1 TM) \\
\hline Step 3: GlcN-PI acyltransferase ${ }^{\mathrm{b}}$ & GWT1 YJL091c (PIG-W 32\%) & Acylation of GlcN-PI in the ER. & 490aa, 0.088, 12 TM; (504aa, 13 TM) \\
\hline \multirow{2}{*}{$\begin{array}{l}\text { Step 4: Mannosyl-transferase } 1 \\
\text { (GPI-MT-1) }^{\mathrm{c}}\end{array}$} & GPII4 YJR013w (PIG-M 38\%) & Addition of Man1 to GlcN-acyl-PI & 403aa, 0.025, 8 TM; (423aa, 8 TM) \\
\hline & PBN1 YCL052c (PIG-X, 16\%) & Stabilization of Gpi14/PIG-M. & 416aa, 0.038, 1 TM; (252aa, SS, $1 \mathrm{TM})$ \\
\hline Step 5: GPI-MT-2 ${ }^{\mathrm{d}}$ & GPII8 YBR004c (PIG-V 31\%) & Addition of Man2 & 433aа, 0.067, 8 TM; (493aа, 9 TM) \\
\hline Step 6: GPI-EtN-P-T1 ${ }^{\mathrm{e}}$ & MCD4 YKL165c PER2 (PIG-N 30\%) & $\begin{array}{l}\text { Addition of phosphorylethanolamine } \\
\text { to Man1 }\end{array}$ & 919aa, 0,096,14 TM; (931aa, 15 TM) \\
\hline Step 7: GPI-MT-3 ${ }^{\mathrm{f}}$ & GPI10 YGL142c PER13 (PIG-B 28\%) & Addition of Man3 & 616aa,-0.011 9 TM; (554aa, 7 TM) \\
\hline Step 8: GPI-MT-4 ${ }^{\mathrm{g}}$ & SMP3 YOR149c (hSMP3 30\%) & Addition of Man4 & 516aa, 0.051, 7 TM; (579aa, 4 TM) \\
\hline Step 9: GPI-EtN-P-T3 ${ }^{\text {h }}$ & GPI13 YLL031c (PIG-O 29\%) & $\begin{array}{l}\text { Addition of phosphorylethanolamine } \\
\text { to Man3 }\end{array}$ & 1017aa, 0.157, 13 TM; (1089aa, $14 \mathrm{TM})$ \\
\hline \multirow[t]{2}{*}{ Step 10: GPI-EtN-P-T2 ${ }^{\mathrm{h}}$} & GPI7 YJL062c LAS21 (hGPI7 25\%) & $\begin{array}{l}\text { Addition of phosphorylethanolamine } \\
\text { to Man2 }\end{array}$ & 830aa, 0.044, 9 TM; (975aa, $11 \mathrm{TM})$ \\
\hline & GPIII YDR302w (PIG-F 30\%) & $\begin{array}{l}\text { Necessary for EtN-P-T2 in yeast } \\
\text { (and EtN-P-T3 in mammals) }\end{array}$ & 219aa, 0.032, 4 TM; (219aa, 6 TM) \\
\hline \multirow[t]{5}{*}{ Step 11: GPI-Transamidase } & GPI8 YDR331w (PIG-K 56\%) & $\begin{array}{l}\text { Catalytic subunit, homologous to } \\
\text { cysteine proteases }\end{array}$ & $\begin{array}{l}411 \mathrm{aa}, 0.063, \mathrm{SS}^{9}, 1 \mathrm{TM} \\
\text { (395aa, SS, } 1 \mathrm{TM})\end{array}$ \\
\hline & GAA1 YLR088w END2 (GPAA1 28\%) & Can bind the GPI lipid substrate & 614aa, 0.057, $6 \mathrm{TM}$; (621aa, $7 \mathrm{TM})$ \\
\hline & GPII7 YDR434w (PIG-S 23\%) & & 534aa, 0.04, 2 TM (555aa, 2 TM) \\
\hline & GPI16 YHR188c (PIG-T 30\%) & May gate the access to the catalytic site & 610aa, $0.151, \mathrm{SS}, 1 \mathrm{TM} ;(578 \mathrm{aa}, \mathrm{SS}, 1 \mathrm{TM})$ \\
\hline & GAB1 YLR459w CDC91 (PIG-U 30\%) & & 394aa, 0.078, 8 TM; (435aa, 9 TM) \\
\hline Step 12: GPI-Inositoldeacylase & BST1 YFL025c (PGAP1 31\%) & $\begin{array}{l}\text { Removes acyl from inositol after the } \\
\text { GPI has been added to protein }\end{array}$ & 1029aa, 0.060, 8 TM; (922aa, 6 TM) \\
\hline Step 13: GPI-remodelase & GUP1 YGL084c & $\begin{array}{l}\text { May add C26:0 to } s n-2 \text { of } \\
\text { diacylglycerol anchors }\end{array}$ & $560 \mathrm{aa}, 0.137,10 \mathrm{TM}$ \\
\hline $\begin{array}{l}\text { Step 14: GPI-Protein-Acyl- } \\
\text { transferase }\end{array}$ & CWH43 YCR017c (PGAP2 31\%) & & 953aа, 0.144, 19 TM: (254aа, 5 TM) \\
\hline
\end{tabular}

${ }^{\mathrm{i}} \mathrm{SS}=$ cleavable N-terminal signal sequence.

${ }^{\text {a }}$ UDP-GlcNAc: PI $\alpha 1-6$ GlcNAc-transferase.

b Acyl-CoA: GlcN-PI acyltransferase.

c Dol-P-Man: GlcN-acyl-PI $\alpha 1-4$ Mannosyltransferase.

d Dol-P-Man: Man-GlcN-acyl-PI $\alpha 1-6$ Mannosyltransferase.

e Phosphatidylethanolamine: $\mathrm{Man}_{\mathrm{x}}$-GlcN-acyl-PI phosphorylethanolamine transferase.

${ }^{\mathrm{f}}$ Dol-P-Man: $\mathrm{Man}_{2}$-GlcN-acyl-PI $\alpha 1-2$ Mannosyltransferase.

${ }^{g}$ Dol-P-Man: $\mathrm{Man}_{3}$-GlcN-acyl-PI $\alpha 1-2$ Mannosyltransferase.

${ }^{\mathrm{h}}$ Phosphatidylethanolamine: $\mathrm{Man}_{\mathrm{x}}$-GlcN-acyl-PI phosphorylethanolamine transferase.

inositol ring, but during purification and analysis of GPI lipids the acyl may migrate on the inositol ring to other positions through spontaneous transacylation [49]. The donor substrate for inositol acylation in Saccharomyces cerevisiae is acyl-CoA [50] while in mammalian cells an acyl-CoA-dependent as well as an acyl-CoA-independent pathway may coexist $[51,52]$. In most organisms the acylation reaction occurs before the addition of the first mannose residue (Man1, Figs. 1A and 2). A gene encoding an acyltransferase adding fatty acids to inositol was recently identified and named PIG-W. PIG-W is a very hydrophobic ER protein [53]. The affinity purified enzyme had acyl-
CoA-dependent inositol acyltransferase activity in vitro. PIG-W deficient cells are still able to make GPI lipids containing mannose and EtN-P on Man1. Based on the location of conserved regions and the predicted TM regions it was suggested that the catalytic site resides in the ER lumen. This suggests that PIGlcN can flip into the ER lumen and inositol acylation is not required for this flip reaction to occur [53].

\subsubsection{Step 4: addition of Man1}

The first mannose is transferred from dolicholphosphomannose (Dol-P-Man) to GlcN-acyl-PI by PIG-M/Gpi14p [54]. 
PIG-M contains a lumenally oriented, conserved DXD motif that is found in many Dol-P-Man utilizing enzymes. Mutation of this motif abrogates the catalytic activity of the enzyme, suggesting that its catalytic site resides in the ER lumen. This finding made it clear that the early GPI intermediates have to flip from the cytosolic leaflet to the ER lumen before the addition of the first mannose residue. A recent study from the lab of Taroh Kinoshita revealed that PIG-M/Gpi14p depends on a second subunit, PIG-X, a 252 aa long type I transmembrane glycoprotein forming a complex with PIG-M, thereby stabilizing it. PIG-X shows $16 \%$ identity with the C-terminal part of yeast $P B N 1$, an essential gene [55]. Pbnlp also is a type I integral membrane, which is multiply $\mathrm{N}$-glycosylated despite the apparent lack of a signal sequence in its primary sequence [56]. The cotransfection of PBN1 and GPI14 restored surface expression of the GPI protein CD59 to mammalian PIG-X-deficient mutants, whereas transfection of either PBN1 or GPI14 alone had no effect [55]. No other Dol-P-Man dependent mannosyltransferase had so far been reported to consist of a heterodimeric complex. PBN1 had been described as being specifically required for the autocatalytic processing of the vacuolar protease B (Pbrlp) [56]. $P B N 1$ is essential whereas $P R B 1$ is not. This had suggested that PBN1 had a second, essential function [56], which now seems to be identified. Further studies will be required to determine if maturation of Prb1p requires GPI anchor biosynthesis in general or if $P B N 1$ plays a more specific role in this maturation process.

\subsubsection{Step 5: addition of Man2}

Complementation cloning has recently identified the PIG-V as the transferase adding Man2 of the GPI core structure [57]. Mutation of conserved residues within the two hydrophilic, lumenally oriented, conserved regions abolishes activity, indicating that Man2 also is added on the lumenal side of the ER membrane. The yeast homologue of PIG-V is GPI18, an essential gene, and gpil $18 \Delta$ mutants are rescued by the expression of mammalian PIG-V [57].

\subsubsection{Step 6: Addition of EtN-P onto Man1}

The EtN-P-transferase transferring EtN-P to Man1 is encoded by MCD4 in yeast and its ortholog PIG-N in mammals (Fig. 2) [58,59]. Phosphatidylethanolamine (PE) serves as a donor of the EtN-P group [60]. MCD4 is essential and can be inhibited by YW3548 [61]. Addition of this inhibitor or the depletion of Mcd4p arrest the growth of yeast cells and lead to the accumulation of the abnormal GPI lipid M2* (Man $\alpha 1-$ $6 \mathrm{Man} \alpha 1-4 \mathrm{GlcNH}_{2}-$ inositol- $\mathrm{PO}_{4}$-lipid), indicating a problem with the addition of Man3 (Figs. 1A and 2) $[9,59,61,62]$ and suggesting that Gpi10p, the mannosyltransferase adding Man3, strongly prefers substrates carrying an EtN-P substituent on Man1. Indeed, overexpression of Mcd4p can improve the growth of yeast cells in the presence of low concentrations of YW3548, while overexpression of Gpi10p is comparatively inefficient $[59,62]$. While these data indicate that Mcd4p helps Gpi10p by providing an optimal substrate, they can't rule out the possibility that Mcd4p would influence the function of Gpi10p indirectly, e.g., by channeling substrates into Gpi10p or by regulating PE levels in the ER. There indeed is a genetic link between MCD4 and PE biosynthesis: The mcd4-P301L and mcd4-174 alleles render cells temperature sensitive (ts) when combined with psd1 1 , PSD1 being the phosphatidylserine decarboxylase, by which the bulk of PE is made. The mcd4P301L mutation was claimed to not affect GPI biosynthesis. Temperature sensitivity of $m c d 4 p s d l \Delta$ mutants could be reverted by the addition of ethanolamine and choline to the media [63]. Temperature sensitivity of another $m c d 4$ allele named $f_{s r} 2-1$ is suppressed by overexpression of $P S D 1, P S D 2$ or ECM33 [64]. Thus, Mcd4p may also play a role in PE metabolism. Recent data indicate that the EtN-P group added by $\mathrm{Mcd} 4 \mathrm{p}$ is required for the recognition of GPIs by Gpi10p as well as by the transamidase complex and that this EtN-P group plays a role in ER to Golgi transport of GPI proteins and also in ceramide remodeling [65].

\subsubsection{Step 7: addition of Man3}

The addition of Man3 is mediated by Gpi10p/PIG-B (Fig. 2). Gpi10p requires substrates containing an EtN-P residue on Man1, whereas this is not true for Gpi10p homologues of most protozoa, since GPI anchors of these organisms do not have an EtN-P on Man1. Deletion of PIG-N, the enzyme that adds EtN$\mathrm{P}$ to Man1 in mammalian cells, does not completely abolish the addition of GPIs to proteins [59]. This may explain why the addition of YW3548, an inhibitor of PIG-N and Mcd4p does not significantly affect GPI protein expression in mammals or T. brucei, whereas it blocks the growth of yeast $[59,61]$.

\subsubsection{Steps 8 and 9: addition of Man4 and of EtN-P to Man3}

Yeast Gpi13p and mammalian PIG-O are required for the addition of the EtN-P onto Man3 (Fig. 2) [66,67]. Contrary to PIG-O, Gpi13p requires a forth mannose (Man4) to be present on its substrate [68]. This by itself offers an explanation, why Smp3p, the mannosyltransferase adding the Man4, is essential in yeast and in C. albicans $[68,69]$. The human SMP3 homologue (hSmp3) is not expressed in many human cell lines, which however have no problem in GPI anchoring [70]. This argues that PIG-O does not require substrates with Man4. Another difference between yeast and man concerns the role of GPI11. PIG-O/GPI13 is assumed to be the catalytic entity adding EtN-P to Man3 because MCD4/PIG-N, GPI7/hGPI7, and GPI13/PIG-O form a gene family containing regions homologous to various phosphodiesterases and nucleotide pyrophosphatases and because there is good evidence for MCD4/PIG-N and GPI7/hGPI7 being the EtN-P transferases for Man1 and Man2, respectively $[9,59,71]$. PIG-F, the mammalian homologue of GPI11, is absolutely required for the addition of EtN-P to Man3 in mammalian cells because PIG-O is unstable in its absence $[67,72,73]$. In contrast, GPII1 has been reported to be dispensable for the addition of EtN-P to Man3. This was based on the finding that gpil1 $\Delta$ cells, rescued by heterologous expression of human PIG-F, still add EtN-P to Man3, but not to Man2 suggesting that in yeast Gpil1p may be required to stabilize Gpi7p [72]. Yet, GPI11, an essential gene, must do something more than help stabilizing Gpi7p, which is nonessential. In our opinion, Gpil1p may be required to stabilize Gpi13p also in yeast, since the aforementioned gpil1 $\Delta$ mutant 
overexpressing human PIG-F cannot be assumed to fully reflect Gpi11p deficiency. It is conceivable that human PIG-F, heterologously expressed in yeast, is apt to stabilize Gpi13p but not Gpi7p, thus rescuing gpill $\Delta$ cells and at the same time imparting a gpi $7 \Delta$ phenotype onto them.

Curiously, deletion of PIG-O in mammalian cells does not completely abolish GPI anchor addition to proteins and a minor GPI lipid carrying EtN-P on Man3 is still detectable in the PIG$\mathrm{O} \mathrm{KO}$ cells, suggesting the existence of a minor PIG-O-independent pathway for the addition of EtN-P to Man3 [67]. Thus, in mammalian cells, two pathways lead to the addition of EtN-P onto Man3, both being dependent on PIG-F [67] but only the major one being dependent on PIG-O. It may be speculated that the minor pathway is dependent on hGPI7. In yeast, no such minor pathway has been described and the overexpression of Gpi7p or Mcd4p cannot rescue the growth phenotype of Gpi13p depleted cells [9].

\subsubsection{Step 10: addition of EtN-P to Man2}

GPI7 and hGPI7 are believed to encode the transferase that adds EtN-P from PE onto Man2 of the GPI lipid (Figs. 1 and 2) $[9,71,73]$. Gpi7p a is a glycosylated integral membrane protein with 9-11 predicted TMs in the C-terminal part and a large, hydrophilic N-terminal ectodomain. The bulk of Gpi7p was claimed to be present in a high molecular weight complex at the plasma membrane, because treatment of spheroplasts with protease eliminated the high molecular weight form of Gpi7p [71]. This obviously was not compatible with the proposed function of Gpi7p as EtN-P transferase for GPI biosynthesis in the ER, and with the fact that this activity is easily detected in the microsomal in vitro system [9]. However, recent data show that a C-terminally tagged version of Gpi7p runs at an apparent molecular weight of about $90 \mathrm{kDa}$ after denaturation in SDS at $4{ }^{\circ} \mathrm{C}$, while it runs at $220 \mathrm{kDa}$ after denaturation in SDS at $95^{\circ} \mathrm{C}$ [74] (Y. Jigami, personal communication). Thus, Gpi7p may aggregate with plasma membrane proteins upon heating in SDS and the previous interpretation of data may be incorrect: For the moment it seems that Gpi7p may reside in the ER, which also is in agreement with the recently reported ER localization of a GFP-tagged Gpi7p [75] and with the recent localization of the human homologue hGPI7 to the ER [73]. While Gpi7p clearly seems to be important for the addition of EtN-P on Man2 of the GPI structure (Figs. 1A and 2), it is not clear if the GPI anchored proteins contain this side chain $[9,71]$. The study of EtN-P side chains is complicated by the fact that these side chains are chemically labile, specially the one on Man2 and that the stability of EtN-P substituents is influenced by substituents on neighboring mannoses [9]. The three putative EtN-P transferases Gpi13p, Gpi7p and Mcd4p cannot replace each other even when overexpressed $[9,67]$. Genetic manipulations to increase PE levels in gpi7 $\Delta$ cells by overexpression of $P S D 1$ restore cell growth at $37^{\circ} \mathrm{C}$ without restoring the addition of a substituent to Man2 [9].

Apart from exhibiting a deficiency in the EtN-P transfer onto Man2 detected in vivo and in vitro, gpi7 $\Delta$ mutants transport GPI proteins from the ER to the Golgi more slowly than wild type. Moreover, gpi $7 \Delta$ cells are deficient in remodeling of GPI proteins outside the ER (see below) and are calcofluor white sensitive at $37^{\circ} \mathrm{C}$, indicating a problem with cell wall biosynthesis [76].

\subsubsection{Further genes to be discovered}

The list of genes in Table 1 may not be complete as there still are mutants, which fail to express GPI proteins at the cell surface and in which all known PIG and gpi genes seem to be intact [77]. One can speculate that there would be a need for a flippase or scramblase able to flip PI-GlcN so that its hydrophilic headgroup is oriented towards the ER lumen. Also, flippases for acyl-CoA, Dol-P-Man and PE may be involved, although they might affect not only the GPI pathway and therefore be essential even in mammalian cells. On the other hand, these trans-bilayer movements of lipids are difficult to measure biochemically and it cannot be excluded that they occur spontaneously. Furthermore, functionally redundant components or regulatory proteins involved in the biosynthetic steps enumerated in Table 1 may have escaped detection so far, since their mutation would not compromise the surface expression of GPI proteins and they therefore would not be identified in mutant screens.

\section{Addition of GPI lipids to proteins}

Genetic and biochemical approaches have so far identified 5 proteins that encode the subunits of the transamidase complex, which transfers the GPI lipid to the newly made GPI protein in the ER (step 11, Fig. 2 and Table 1) [78-82]. All 5 proteins are essential in yeast and, in the mammalian system, all five are required for the nucleophilic attack on the $\omega$ site residue $[81,82]$. GPI8/PIG-K and GPI16/PIG-T encode type I ER membrane proteins with large lumenal domains and a single TM [79-81]. Gpi8p has 25-28\% homology to a family of cysteine proteinases and the mutation of Cys and His predicted to be active site residues by sequence comparison with related proteases yields non-functional GPI8 alleles [83,84]. Moreover, purified trypanosomal Gpi8p was shown to contain proteolytic activity towards appropriate peptide substrates [85]. Gpi16p is linked through a functionally important and conserved disulfide bridge to Gpi8p [86,87]. Gpi16p has been proposed to form a funnel that gates the access of proteins to the active site of the Gpi8p protease and thus contributes to the specificity of the GPI anchor addition [13]. GAAl encodes a $70 \mathrm{kDa}$ ER protein with an uncleaved N-terminal signal sequence, a large, hydrophilic, lumenal domain, followed by several TMs $[81,88]$. Its last TM is required for binding the GPI lipid substrate into the transamidase complex [89]. Gpi17p/PIG-S is predicted to be mainly lumenal with its $\mathrm{N}$ - and C-terminal ends both being cytosolic. Gablp is a very hydrophobic protein with many TMs $[82,90]$. While Gaalp, Gpi8p and Gpi16p are common to all eukaryotic organisms, Gpi17p and Gablp are absent from trypanosomatids, which latter possess two unrelated integral membrane proteins of similar membrane orientation, TTA1 and TTA2 instead [91]. The mammalian complex made of the five aforementioned subunits, when purified from digitonin extracts, is able to hold substrate proteins, which can be removed by washing with NP-40 [86].

As judged by staining of the SDS-PAGE gel, the purified mammalian transamidase complex contains all 5 subunits in 
comparable amounts [82]. A recent genome wide analysis of protein expression levels in yeast showed that a cell growing on rich media contains 1560, 1680 and 7520 copies of Gpi8p, Gpi16p and Gpi17p, while the signals for Gaa1p and Gab1p remained extremely low and undetectable, respectively $[75,92]$. Yet, in the detergent purified yeast complex, as judged by silver staining, the amount of Gaalp was similar to the one of Gpi8p and Gpil6p [80] and genomic tagging of GAB1 with GFP resulted in ER-localized fluorescence that was readily detected by light microscopy [90]. Thus, it is likely that, as in mammalian cells, Gaalp, Gpi8p, Gpi16p and Gablp are present at comparable amounts, whereas there may be supernumerary copies of Gpi17p. At least for Gpi8p it has been demonstrated that it is stabilized by the interaction with other subunits [80]. Similar observations have been made in the mammalian system where it was shown that Gpi16p is required for the stabilization of the other subunits [81].

The molecular weights of all five known yeast transamidase subunits adds up to about $330 \mathrm{kDa}$ which is less than the 430-650 kDa observed in blue native gel electrophoresis [80], but this technique cannot be taken as a reliable indicator of the true molecular mass of the complex [93]. Based on genetic interactions between transamidase subunits it recently was proposed that the yeast transamidase complex, in contrast to the mammalian complex, may consist of two subcomplexes: one containing Gpi8p, Gpil6p, and Gaalp and the other containing Gab1p and Gpi17p [90]. In keeping with this proposal, the use of GST-Gpi8p as the biochemical bait allowed the affinity purification of a Gpi8pGpi16p-Gaalp three-component subcomplex [80]. Also, random and site directed mutagenesis generated mutations in several highly conserved amino acids but did not yield non-functional alleles of Gpi17p and a saturating screen did not yield any dominant negative alleles of Gpi17p. Moreover, on density gradients, the bulk of Gpi17p does not cosediment with Gpi8p and Gpi16p. These data suggest that yeast Gpi17p may be able to exert its GPI anchoring function without interacting in a stable and continuous manner with the other GPI-transamidase subunits [94]. Further studies are required to understand how the two subcomplexes of yeast interact and how the five subunits cooperate in order to transfer the GPI lipid onto nascent proteins.

\section{Modifications of the GPI anchor after attachment to proteins}

\subsection{Removal of the acyl chain from inositol}

As mentioned, GWT1 has recently been identified as the acyltransferase adding palmitic acid onto the 2-OH group of D-myo-inositol $[53,95]$. In yeast, this acyl chain is found on all but the earliest GPI intermediates, but it is not present on the mature GPI anchor. When analyzing anchor lipids from cells metabolically labeled with $\left[{ }^{3} \mathrm{H}\right]$ inositol for only very short periods, one not only finds PI but also traces of acyl-PI [49]. This suggests that in yeast the acyl moiety may be removed shortly after the addition of the GPI to proteins by the transamidase. In an elegant study, a gene coding for this deacylase activity, PGAP1, has recently been identified in mammalian cells [48]. For this, the authors exploited the fact that GPI anchors cannot be cleaved by PI-PLC, when the inositol is acylated. Thus, GPI proteins can be removed by PI-PLC treatment from the surface of normal, but not PGAP1-deficient cells. PGAP1 is a huge ER protein with 6 TMs and a large, lumenally oriented hydrophilic domain, which contains a conserved lipase motif. Mutation of a conserved serine of the lipase motif destroys the inositol deacylase activity. The yeast homologue of PGAP1 is BST1 [48]. Deletion of PGAP1 compromises the export of GPI proteins from the ER to the Golgi [48]. Mutations in BST1 generate a similar phenotype in yeast: bst1 (per17-1) cells display a delayed Golgi maturation of Gas1p whereas CPY as well as two other membrane proteins, alkaline phosphatase (ALP) and carboxypeptidase S (CPS) undergo Golgi maturation at a normal rate [96]. Per17-1 cells also induce an unfolded protein response (UPR) and are hypersensitive to the overexpression of misfolded proteins [96]. The role of Bst1p as an inositol deacylase thus explains the specific transport defect of GPI proteins of bst1 (per17-1) cells. It seems that the removal of the acyl from inositol is a prerequisite for efficient transport of GPI proteins from the ER to the Golgi also in yeast. BST1 was found to be important for ER associated degradation of a misfolded, soluble protein (ERAD) and it was claimed that transport of such proteins to the Golgi may be a prerequisite for degradation [96,97]. Indeed, an extensive recent study on the degradation of an artificially generated, misfolded form of Gas1p (Gas1*p) confirms the role of Bstlp in its degradation [98]. Folding incompetent Gas1*p gets GPI anchored and is rapidly degraded in proteasomes. It reaches proteasomes through an unconventional pathway not involving the known E3 ubiquitin ligases involved in the classical lumenal and cytosolic ERAD pathways. Yet, The degradation of Gas $1 * \mathrm{p}$ is strongly delayed in $b s t 1 \Delta$ or $\sec 18$ cells. The data suggest that Gas $1 *$ p requires deacylation by Bst1p and trafficking through the Golgi, whereas the effect of BST1deletion on the degradation of soluble misfolded proteins may be indirect [98].

\subsection{Remodeling of lipid moieties of GPI proteins}

In several organisms the occurrence of rare lipid species on GPI anchors has been explained by lipid remodeling. This term is used for instances in which the lipid moiety of the free GPI lipid or the GPI anchor attached to a protein is modified. By definition, one can infer a remodeling event if early intermediates of the GPI lipid biosynthetic pathway, e.g., GlcN-acyl-PI, carry a different lipid moiety than later intermediates or proteinbound GPI anchors. Practically, however, it often is not trivial to obtain sufficient material of the earliest GPI intermediates for analysis. In some cases there are significant amounts of GlcNacyl-PI, but the bulk of this material may not be destined for GPI anchor biosynthesis, but rather serve to generate free GPI lipids. This seems to be the case for many mammalian cell lines that produce much more GPI lipids than what is needed for protein anchoring [99-102]. In these cases it needs to be demonstrated that an early intermediate really is in the pathway leading up to protein-anchoring GPI structures. In yeast, where no early GPI intermediates are detectable, information can only be gained 
from GPI lipids accumulating in cells having mutations in the biosynthetic pathway.

The lipid moieties of mature GPI-anchors of $S$. cerevisiae usually do not contain the diacylglycerol present on the GPI lipid at the stage when it is transferred by the transamidase to GPI proteins and which probably contains the C16 and C18 fatty acids found in yeast PI $[49,103]$. Most mature GPI proteins of yeast contain a ceramide moiety, whereas a minor fraction contains a modified diacylglycerol containing C26:0 in sn-2 [8,49] (Fig. 1B). It has to be noted that ceramides of $S$. cerevisiae almost exclusively contain C26 fatty acids. Thus, all mature GPI proteins of yeast contain large lipid moieties with C26 or hydroxylated C26 fatty acids, either in the form of a ceramide or a special diacylglycerol and these lipids are introduced by remodeling enzymes that replace the primary lipid moiety of the anchor.

Ceramides are also found in the GPI anchors in certain plants, (e.g., pears), Trypanosoma cruzi, Paramecium, Aspergillus fumigatus and Dictyostelium [12], sometimes as the sole anchor lipid [104]. Recent studies show that, similar to yeast, the first steps of GPI biosynthesis in T. cruzi do not use ceramide as the lipid support, suggesting that ceramide is added by remodeling at a later step not only in yeast but also in T. cruzi [105].

The yeast remodeling activity introducing ceramide (ceramide remodelase) can be monitored by metabolic labeling experiments using tritiated DHS ( $\left.\left[{ }^{3} \mathrm{H}\right] \mathrm{DHS}\right)[106]$. When given to cells, this tracer is rapidly taken up and is incorporated into all sphingolipids as well as ceramide-containing GPI proteins. By metabolic labeling experiments in different secretion mutants with $\left[{ }^{3} \mathrm{H}\right]$ DHS one finds that ceramide remodelase activity is present in both, the ER and beyond, i.e., the Golgi or the plasma membrane [106]. Ceramides with hydroxylated fatty acids (C26$\mathrm{OH})$ are only introduced in the Golgi while all other types of anchor lipids can be attached in the ER. Even on mature proteins, the ceramide moieties continue to be turned over [106]. The identity of the enzymes introducing ceramide is presently not known, but it is clear that this activity is different from Aurlp, the inositolphosphorylceramide synthase, which may perform a formally similar reaction [107]. Incidentally we found that gpi7 $\Delta$ cells have very little ceramides with hydroxylated fatty acids $(\mathrm{C} 26-\mathrm{OH})$ [71]. It may be that the Golgi remodelase introducing this ceramide needs GPI protein substrates carrying EtN-P on Man2 of their anchor, but as it is difficult to detect this substituent on GPI proteins [9], it presently is not possible to show that Golgi remodeled proteins carry EtN-P on Man2. Many yeast strains, which have deletions in genes of unknown function have been tested for a deficiency in the remodeling of GPI anchors in this laboratory using a brute force screen. Above all, strains deficient in genes showing some homology with phospholipases $\mathrm{A}, \mathrm{B}$ or $\mathrm{C}$, with enzymes synthesizing or utilizing ceramides, with acyltransferases, or with other proteins binding acyl-CoA were tested. Part of this effort has been published on the web by the EUROFAN2 lipid node at http://mips.gsf.de/proj/ eurofan/eurofan_2/n7/conzelmann.html and many more strains have been tested since. Among all tested strains, only GUP1 could clearly be shown to be involved in GPI anchor remodeling, as it is essential for the synthesis of the C26:0-containing diacylglycerol anchors (step 13, Table 1) [108]. Gup1p is an ER membrane protein with multiple membrane spanning domains harboring a motif that is characteristic of membrane bound $O$-acyl-transferases (MBOAT). Gupls cells make normal amounts of GPI proteins but most mature GPI anchors contain lyso-PI, others possess PI with conventional C16 and C18 fatty acids. The incorporation of the normal ceramides into the anchors is also disturbed. As a consequence, the ER to the Golgi transport of the GPI protein Gas1p is slow and mature Gas 1p is lost from the plasma membrane into the medium. Gup $1 \Delta$ cells have fragile cell walls and a defect in bipolar bud site selection. GUP1 function depends on the active site histidine of the MBOAT motif. GUP1 is highly conserved amongst fungi and protozoa and the gup $1 \Delta$ phenotype is partially corrected by GUP1 homologues of Aspergillus fumigatus and Trypanosoma cruzi. Thus, it seems likely that the Gup1p mediated remodeling of GPI anchors also occurs in a similar way in other fungi and protozoa.

A further remodelase has also been identified recently in mammalian cells (step 14, Table 1). PGAP2 is necessary to prevent the hydrolytic removal of the lipid moiety of GPI anchored proteins [109]. PGAP2 is an integral membrane protein of the Golgi and is widely conserved in eukaryotes, but without any recognizable motif that would give a clue to its mode of action. In cells deleted for PGAP2, the GPI-proteins' diradylglycerol moieties are first converted to lyso-forms before they exit the trans-Golgi-network. Second, after GPI proteins with lyso-lipids have been transported to the plasma membrane, the lyso-lipids are cleaved by a phospholipase D. By consequence, deficiency of PGAP2 causes GPI proteins to be secreted. PGAP2 may be involved in the exchange of acyl moieties on $s n-2$ but other modes of action are equally possible [109]. S. cerevisiae contains a PGAP2 homologue, Cwh43p, the N-terminus of which shows about 25\% identities spread over almost the entire length of PGAP2. Beyond this PGAP2 homology domain, Cwh43p contains a 500 aa long C-terminal extension, which also contains numerous transmembrane domains. This C-terminal part of Cwh43p in turn is about $25 \%$ identical with another human hypothetical membrane protein. Thus, it is possible that the CWH43 function is carried by two separate proteins in mammals. Cwh43p may serve a similar function in yeast as PGAP2, since $c w h 43 \Delta$ cells show a cell wall phenotype, are calcofluor white hypersensitive and secrete GPI proteins such as Cwp1p [110].

\subsection{Addition of Man5}

A fifth mannose is added to $20-30 \%$ of GPI proteins in the Golgi (Fig. 1A), the 5th mannose being added either in $\alpha 1-2$ or in $\alpha 1-3$ linkage $[8,111]$. The data indicate that there must be an $\alpha 1,3$ mannosyltransferase in the cis-Golgi and an $\alpha 1,2$ mannosyltransferase in the trans-Golgi, but the genes coding for these activities have not been identified [111]. We also tested strains carrying multiple deletions in related, verified or putative $\alpha 1,2-$ or $\alpha 1,3$-mannosyltransferases [112]. Thus the addition of the 5th mannose in $\alpha 1-2$ linkage in the kre $2 \Delta$ ktr $1 \Delta$ ktr $2 \Delta k t r 3 \Delta$ yur $1 \Delta k \operatorname{tr} 6 \Delta$ mnn $2 \Delta$ septuple mutant was normal and addition in $\alpha 1-3$ linkage in the mnn $1 \Delta$ mnt $2 \Delta$ mnt $3 \Delta$ mnt $4 \Delta$ quadruple 
mutant was equally normal (Patrick Jung, Howard Bussey and Andreas Conzelmann, unpublished).

\section{Export and intracellular sorting of GPI proteins}

\subsection{Transport from ER to the Golgi}

GPI anchored proteins leave the ER in COPII-coated vesicles and travel via the Golgi to the plasma membrane [113]. Yeast GPI proteins failing to be attached to a GPI anchor are retained in the ER, probably through signals contained in the uncleaved GPI attachment signal $[114,115]$. Unanchored GPI proteins are eventually degraded, as had been found also in mammalian cells. GPI protein export out of the ER has been shown to be influenced by several factors that do not have a general impact on protein transport out of the ER, namely ceramides, the Emp24p complex, Yos9p and COP I [116-123]. The role of Yos9p in the transport of Gaslp has however been questioned recently [124-126]. Moreover, Gas 1p is sorted from other plasma membrane proteins in the ER and packaged into different vesicles than Gap1p, a amino acid permease of the plasma membrane [127,128]. It is not clear if Gas1p reaches the same Golgi compartments as Gap 1p and soluble cargo proteins.

\subsection{Transport from Golgi to the plasma membrane}

Cargo is carried from the late Golgi to the surface in several different types of vesicles [129-131]. Vesicles of higher density contain the soluble secretory enzyme invertase, acid phosphatase and most of exoglucanase activity; vesicles of lower density contain Pmalp, the plasma membrane $\mathrm{H}^{+}$-ATPase and Gaslp [132]. At some stage of the secretory pathway GPI proteins have to be sorted away from the vacuolar hydrolases. This sorting may be dependent on ergosterol since Yps1p, a GPI anchored protease, is found normally at the plasma membrane, but is partially mistargeted to the vacuole in $\operatorname{erg} 6 \Delta$ mutants [133]. The separation of vacuolar and GPI proteins however may not be totally efficient, since the transfection of GFP-tagged GPI proteins has been observed to lead to vacuolar fluorescence also in wt backgrounds [134] (Régine Bosson, unpublished). It is not clear if GPI proteins enter the vacuoles by endocytosis from the plasma membrane or through a direct transport from the Golgi.

\subsection{Specific destinations of GPI proteins}

Some GPI proteins are targeted to specific sites of the cell wall. For instance, the putative glycosidase Crh2p is targeted to the base of the mother-bud neck during cytokinesis and this specific targeting depends on septin $(C D C 10)$, actin polarization $(C D C 42)$ and mutation of genes that are required to bring chitin synthase III (CHS3) to the same location, namely mutations in BNI4, CHS5, SBE2 and SBE22 lead to the accumulation of Crh2p in intracellular vesicles. An other GPI protein, Cwp1p however reaches the surface independently of these genes [134].

Another example of a highly specific targeting of a GPI protein is $E G T 2$. Egt2p localizes to the septum and is required for septum degradation and cell separation. It encodes a GPI protein that is specifically expressed in daughter cells at the early G1 phase, and it has been proposed that Egt2p is a glucanase or a regulator of a glucanase [135-137]. A recent study shows that Egt2p is targeted to the septum region in wild type cells but is dispersed over the whole cell surface of the daughter cell in gpi7D mutants [74]. Deletion of GPI7 did however not interfere with the septum localization of Eng1p, another daughter specific endoglucanase, which however is not anchored in the membrane. GPI7 dependent targeting to the septum could be conveyed to Eng1p by attaching the GPI anchor attachment signal plus 27 amino acids of the $\omega$ minus region of $E G T 2$ to the C-terminal end of ENG1. Deletion of EGT2 partially rescued the growth phenotype of gpi7 $\Delta$ mutants [74]. Together these findings suggest that the cell wall fragility of gpi7 $\Delta$ mutants is due to the aberrant localization of Egt2p in the daughter cell wall, as Egt2p in gpi7s cells may weaken the cell wall at the wrong place and make the daughter cells osmosensitive. It is however not clear yet, if correct targeting of Egt2p requires that an EtN-P on Man2 of the GPI anchor of Egt2p is recognized or if it requires some more general cell wall properties, which are lost in gpi7s.

The trafficking of GPI proteins has been the subject of several recent reviews $[93,138]$.

\subsection{Integration of GPI proteins into the cell wall}

The cell wall of $S$. cerevisiae is made up of an inner glucan layer, an outer mannoprotein coat as well as a small amounts of chitin. As stated in Introduction, many GPI proteins end up as cell wall proteins covalently linked to the $\beta$-glucans. This is also seen in other fungi such as Candida [139-141] but not in Aspergillus $[142,143]$. The linkage region of GPI proteins in S. cerevisiae was elaborated through a pioneering study of Enrico Cabib's and Frans Klis' labs showing that Man1 of GPI anchors is glycosidically linked to $\beta 1,6$ glucan, which in turn is attached to $\beta 1,3$ glucan and chitin [144]. The linking structure was identified as protein-CO-NH- $\left(\mathrm{CH}_{2}\right)_{2}-\mathrm{PO}_{4}-(\mathrm{Man} \alpha 1-3 \mathrm{Man} \alpha 1-2 \rightarrow)$ Man $\alpha 1-2$ Man $\alpha 1-6$ Man- $\beta 1$,6glucan. This structure indicates that the GPI anchor had been cleaved and the GlcN-PI moiety had been lost in the process. On the other hand, a minority of GPI proteins is found to reside at the plasma membrane. The classification of GPI proteins into cell wall proteins (GPI-CWPs) and plasma membrane proteins (GPI-PMPs) has to be regarded as relative rather than absolute, as it only indicates the predominant localization, whereby most GPI proteins can be found in both locations. Nevertheless, specific residues in the $\omega$-minus region seem to favor either cell wall or plasma membrane localization. Basic residues in the region immediately upstream of the GPI attachment site ( $\omega$ ? site) are frequently found in GPI-PMPs such as Yps1p, Plb1p and Gas 1p but are absent from cell wall proteins. Therefore, basic residues close to the $\omega$ ? site were proposed to prevent further processing and integration into the cell wall $[29,145]$. Analysis of a large panel of biochemically verified GPI proteins also suggested that the presence of $\mathrm{V}$, I or $\mathrm{L}$ at $\omega-4$ and $\omega$ 5 as well as of $\mathrm{Y}$ or $\mathrm{N}$ at $\omega-2$ may act as a positive signal for cell wall localization $[31,146]$. These suggestions were born out by a recent study, in which a GPI-PMP was mutated to build a library 
of $509^{\prime} 000$ clones containing mutations in positions $\omega-1$ to $\omega-6$ [147]. The authors transfected the library and screened for clones integrating increased amounts of the GPI-PMP into the cell wall. A large panel of such mutants was sequenced [147]. The study demonstrates that removal of charged residues from positions $\omega-2$ and $\omega-1$ as well as introduction of a hydrophobic amino acid at $\omega$ 4 strongly favor cell wall integration. Cell wall integration however seems also to be influenced by sequences that lie further upstream of the $\omega$-site. Indeed, many yeast GPI proteins contain serine/threonine rich regions of up to several hundred amino acids upstream of their $\omega$-site and it was shown that such Ser/Thr rich sequences promote cell wall integration. The Ser/Thr signal is able to override a dibasic plasma membrane localization signal close to the $\omega$-site. This further signal seems to be exploited by nature as in average the serine and threonine rich region is significantly longer in GPI-CWPs than in GPI-PMPs [148]. The presence of such a region may explain why there are considerable amounts of Gas1p covalently linked to the cell wall $[32,149]$. Long serine and threonine-rich stretches not only favor integration into the cell wall, but they also enable GPI proteins mediating cell adhesion to display their N-terminal domains at the external surface of the cell wall, where they can interact with their ligands [140]. Indeed, artificial shortening of the serine/threonine rich stretch in the EPA1 gene of Candida glabrata abolished its adhesion function, because the N-terminal ligand binding domain of the shortened version of the protein was no more accessible at the cell surface, although it still was covalently linked to glucans [140]. The linking structure elaborated by Kollar et al. [144] showed a covalent link between Man1 (Fig. 1A) of the GPI anchor and a glucose residue being part of a $\beta 1,6$ glucan structure. This suggested a possible transglycosidation mechanism for the attachment of GPI proteins to the cell wall glucans. Recently, two candidate genes for this transglycosidase have been identified [150]. DFG5 and DCW1 are themselves GPI proteins, they are homologous to each other and are homologous to bacterial mannosidases, their $\omega$ minus sequences and Ser/Thr contents suggest that they remain at the plasma membrane. While $d f g 5 \Delta$ and $d c w 1 \Delta$ mutants are fully viable, the double deletion is lethal. The $d c w 1 d f g 5$ double mutants show a "cell wall phenotype", i.e., their cell wall becomes fragile and they secrete Cwplp [150,151]. Further work is necessary to firmly establish these proteins as the transglycosidases that anchor the GPI proteins to the cell wall glucans.

The covalent attachment of heterologous proteins to the yeast cell wall has been exploited to produce transgenic strains for use in food industry and pharmacology. Indeed, S. cerevisiae has "generally regarded as safe" (GRAS) status and can be used for food and pharmaceutical production; it therefore is one of the most suitable microorganism for practical purposes in the development of cell-surface expression systems [152].

\section{Properties and functional roles of yeast GPI proteins}

As mentioned, GPI anchoring is an essential function in yeast [153]. Yet, there is only one GPI protein, which is essential, namely ROT1. Rot $1 \Delta$ mutants can be rescued by $0.6 \mathrm{M}$ sorbitol in the medium [20].
GPI proteins can be grouped into different classes based on their functions. Many GPI proteins of the cell wall help to build and maintain the stretch resistance of cell wall components as the simultaneous deletion of multiple GPI proteins (Ccw12p, Ccw13p, Ccw14p, Tip1p, and Cwp1p) can lead to decreased osmotic stability [154]. Thus, many GPI proteins play a structural role and may give stretch resistance by interacting with glucans and other wall components or by interacting with each other through by noncovalent bonds and disulfide bridges. Other GPI proteins may act as enzymes to make and break glycosidic linkages and are required for elaboration of the cell wall and its reshaping during bud emergence, cell separation, mating or entry into stationary phase. Such a role has been demonstrated for Gas $1 p$, which acts as a $\beta 1,3$ glucan specific transglucosidase $[155,156]$, and are proposed for Egt2p (see above) as well as for Crh1p and Crh2p, two homologous proteins, both of which contain the glycosidase motif PF00722. Similarly, DFG5 and $D C W 1$, contain an $\alpha 1,6$-mannanase motif (PF03663) and are supposed to cleave the Man $\alpha 1,4 \mathrm{GlcN}$ bond of the GPI anchor in order to link GPI proteins covalently to the cell wall glucans (see above). Several GPI proteins have other enzymatic functions, e.g., the phospholipases B PLB1-PLB3, or the aspartyl proteases YPS1-YPS3 and YPS6. Many GPI proteins contain a domain, which is exposed at the surface of the cell wall, and mediate cell adhesion or biofilm formation. In this category we find the flocculins FLO1, FLO5, FLO9 and FLO11, the sexual agglutinins $S A G 1$ and $A G A 1$, and possibly the flocculin related semipauperin family (TIR1-TIR4, TIP1, DAN1, DAN4).

Supplemental Table S1 contains a compilation of potential and confirmed GPI proteins of yeast. It contains the 61 predicted or potential GPI proteins having an N-terminal signal sequence presented by Birgit Eisenhaber at http://mendel.imp. ac.at/gpi/fungi/pred/fungi.scerevisiae.html. but the zinc transporter ZRT3 was removed since it has 6-7 TMs upstream of the GPI anchoring signal and localizes to the vacuole. We added however ECM33 and $A W A 1$, two recently described GPI proteins $[52,157]$.

We tried to see if there are significant correlations between various parameters in Table S1. We noted that the previous positive correlation between Ser/Thr content and tendency to localize to the cell wall [148] was highly significant $(P=0.005$ or 0.027 , depending on the criteria used to define CWPs). Moreover, the cell wall proteins have an isoelectric point (pI) of $4.865 \pm$ 0.2194 whereas the proteins defined as PMPs in the same collection had a $\mathrm{pI}$ of $6.667 \pm 0.9454$, the difference being highly significant. The hydropathy of the N-terminal signal sequence of yeast secretory proteins determines whether they are inserted into the ER cotranslationally by an SRP-dependent, or posttranslationally by an SRP-independent pathway[158]. Gas1p has a signal peptide of low hydropathy and is inserted posttranslationally [158]. We did not find any correlation between the length of the $\mathrm{N}$-terminal signal sequence or its hydropathy and the final localization (cell wall versus plasma membrane).

Given the fact that most GPI proteins are localized at the cell surface, is not amazing, to find that subtle deficiencies of GPI anchoring exhibited by strains deleted in one of the non-essential GPI biosynthesis enzymes (GPI1, ERI1, GPI7 and BST1) 
can perturb cell wall functions such as bud emergence, bud site selection and bud cell separation. Thus, GPI7 and BST1 are required for bipolar bud site selection [159], while gpil $\Delta$ mutants form large, round, multibudded cells with a cell separation defect [160] and gpil, gpi2 $^{t s}$, gpi3 $^{t s}$ and $m c d 4-174$ cells, under restrictive and semi-restrictive conditions, arrest cell growth at non-permissive temperature as large, round, mostly unbudded cells with a $2 \mathrm{C}$ (post-replication) DNA content [58].

\section{Regulation of GPI biosynthesis}

Excellent recent reviews detail the multiple regulatory events inducing various GPI proteins during stress such as anaerobic conditions, low temperature, hypo- and hypertonic conditions, and in the diauxic shift $[23,28]$. Many GPI proteins are transcribed in a cell cycle dependent manner and their location in the cell wall seems to be determined by the polarization of the secretory pathway at the time of their expression (reviewed by Smits et al. [27]). Similarly, several GPI proteins are only expressed strongly when specific genetic programs are activated such as mating, pseudohyphal growth or sporulation. E.g., a- and $\alpha$-agglutinins are GPI anchored, are only expressed when cells prepare for mating and are localized mostly in the shmoo tip [24].

On the other hand, until very recently, the GPI anchoring machinery was regarded as an essential household function. Howzever, together with many other enzymes of the ER, several enzymes that are involved in GPI biosynthesis (GAA1, GPI12, $L A S 21, M C D 4$ ) are induced by the unfolded protein response, suggesting that this response anticipates the difficulties that may arise, when GPI proteins are not properly anchored [161]. More studies are required to understand, why only certain subunits of multisubunit complexes are induced. Moreover, it came as big surprise when it was shown that the GPI pathway could be greatly inhibited by activated (GTP-bound) Ras2p [40]. The studies leading to this discovery were originally concerned with ras signaling [162]. A first study had documented that ERII encodes a 68-amino-acid membrane protein that associates in vivo with GTP-bound Ras2p in a manner that requires an intact Ras-effector loop, suggesting that Eri1p competes with effector proteins for the same binding site on Ras $2 p$. The depletion of Erilp led to the phenotype typical of cells harboring constitutively active Ras $2 p$ alleles and overexpression of Eri1p was found to reduce Ras $2 \mathrm{p}-\mathrm{GTP}$ driven gene expression. Thus, this earlier report concluded that Erilp was an ER based inhibitor of Ras $2 p$ [162]. It was subsequently realized that Eri1p is a subunit of the PI-GlcNAc-transferase and that GTP loaded Ras2p drastically reduced the activity of this enzyme complex [40]. Indeed, the PI-GlcNAc-transferase activity measured in vitro varies 200 fold between microsomes from cells expressing a constitutively active Ras $2 \mathrm{p}$ allele (almost no activity) and the ones from $\operatorname{ras} 2 \Delta$ cells (very high activity), although the activity probably varies within a smaller range in normal cells. What could regulation of GPI biosynthesis be good for? One answer to this question came from the observation that the reduction of GPI-biosynthesis in gpil $\Delta /$ gpil $\Delta$ mutants or a gaal mutant induced filamentous growth and invasive growth, as is seen in eril $\Delta$ cells or cells that harbor hyperactive ras 2 alleles. This and other data strongly suggest, that the PI-GlcNAc-transferase may not only be an inhibitor of Ras $2 p$ but also an effector that allows Ras $2 p-G T P$ to induce filamentous growth through inhibiting PI-GlcNAc-transferase. Things seem however to be more complicated, as Ras $2 p$ binds to PI-GlcNAc-transferase even in eril $\Delta$, i.e., independently of Erilp, and because the invasive/filamentous growth phenotype of gpil $\Delta /$ gpil $\Delta$ mutants is abolished when $R A S 2$ is deleted. Thus, it may be the combined effects of the reduction of PI-GlcNAc-transferase and some signaling through Ras $2 p$, which jointly are responsible for invasive growth under more physiological conditions. The induction of pseudohyphal growth through inhibition of PI-GlcNAc-transferase also is paradoxical as the final output of the pseudohyphal growth program culminates in the expression of Flo11p, a GPI protein [29,146], whose presence by itself is sufficient to induce invasive growth independent of any upstream signaling [163]. It is possible that the pseudohyphal growth of gpi mutants is mediated by a FLO11independent pathway as the one that is active in $s f l \Delta$ mutants [164]. Whatever the exact mechanism, the RAS2 $\leftrightarrow$ PI-GlcNActransferase connection is one more example of the close interknitting and bidirectional cross talk between an enzyme involved in a household function and regulatory elements controlling stress responses. The ras $\leftrightarrow$ PI-GlcNAc-transferase connection is yeast specific, since mammalian ras proteins do not bind to PI-GlcNActransferase [41].

\section{Perspectives}

The identification of genes involved in GPI biosynthesis and GPI attachment to proteins has laid a solid foundation and given the tools to address biological questions. Although in many respects there is more information on GPI anchor biosynthesis and trafficking of GPI proteins in mammalian cells than in yeast, the yeast system is highly attractive because it can be manipulated genetically and allows to combine mutations into a singe cell. Indeed there remain major gaps in our understanding of GPI protein biosynthesis. We do not know for the moment, how yeast cells harmonize the amount of GPI lipids they synthesize with the demand. The enzymes required for GPI biosynthesis and attachment are mostly integral membrane proteins, a property which does not facilitate biochemical experimentation. For most enzymes there is no enzymology, i.e., the enzymes have not been purified, and in many cases their substrate specificity is not known. E.g., it is not quite sure what GPI lipids the transamidase can transfer. Also, we do not know if all GPI proteins receive the same GPI lipid. Furthermore, the quality of bioinformatics predictors of GPI proteins relies on the quality and amount of biochemical experiments establishing the presence of GPI anchors on the proteins used as the training set [7]. The available predictors may not be perfect, since certain GPI proteins, such as YPS1, have very bad scores on the predictor, but clearly possess GPI anchors [165]. The enzymes allowing lipid remodeling are largely unknown, as is the physiological role of the remodeling process. The same is true for the enzymes adding the 5th mannose to the anchor in the Golgi. Also, we do not know, if all proteins are remodeled in equal proportions along the several 
remodeling pathways, or if each GPI proteins is remodeled in a single, distinct way. Furthermore, the retention of non-anchored GPI proteins in the ER as well as the intracellular sorting of anchored GPI proteins in ER, trans-Golgi and the endocytic pathway of yeast are not very well understood. The elaboration and structural reshaping of the cell wall appears to be very complex as it depends on enzymatic reactions, in which neither substrate nor enzyme are freely mobile and the full understanding of the biochemical processes in the cell wall will require unusual and highly sophisticated experimental approaches.

\section{Acknowledgements}

Thanks to Mike Ferguson for sharing a review in press. This work was supported by a grant from the Swiss National Foundation for Science to A.C.

\section{Appendix A. Supplementary data}

Supplementary data associated with this article can be found in the online version at doi:10.1016/j.bbalip.2006.05.015.

\section{References}

[1] M.A. Ferguson, S.W. Homans, R.A. Dwek, T.W. Rademacher, Glycosylphosphatidylinositol moiety that anchors Trypanosoma brucei variant surface glycoprotein to the membrane, Science 239 (1988) 753-759.

[2] S.W. Homans, M.A. Ferguson, R.A. Dwek, T.W. Rademacher, R. Anand, A.F. Williams, Complete structure of the glycosyl phosphatidylinositol membrane anchor of rat brain Thy-1 glycoprotein, Nature 333 (1988) 269-272.

[3] I.W. Caras, G.N. Weddell, M.A. Davitz, V. Nussenzweig, D.W.J. Martin, Signal for attachment of a phospholipid membrane anchor in decay accelerating factor, Science 238 (1987) 1280-1283.

[4] P. Moran, I.W. Caras, Fusion of sequence elements from non-anchored proteins to generate a fully functional signal for glycophosphatidylinositol membrane anchor attachment, J. Cell Biol. 115 (1991) 1595-1600.

[5] L.D. Gerber, K. Kodukula, S. Udenfriend, Phosphatidylinositol glycan (PI-G) anchored membrane proteins. Amino acid requirements adjacent to the site of cleavage and PI-G attachment in the $\mathrm{COOH}$-terminal signal peptide, J. Biol. Chem. 267 (1992) 12168-12173.

[6] C. Nuoffer, A. Horvath, H. Riezman, Analysis of the sequence requirements for glycosylphosphatidylinositol anchoring of Saccharomyces cerevisiae Gas1 protein, J. Biol. Chem. 268 (1993) 10558-10563.

[7] B. Eisenhaber, G. Schneider, M. Wildpaner, F. Eisenhaber, A sensitive predictor for potential GPI lipid modification sites in fungal protein sequences and its application to genome-wide studies for Aspergillus nidulans, Candida albicans, Neurospora crassa, Saccharomyces cerevisiae and Schizosaccharomyces pombe, J. Mol. Biol. 337 (2004) 243-253.

[8] C. Fankhauser, S.W. Homans, J.E. Thomas-Oates, M.J. McConville, C. Desponds, A. Conzelmann, M.A. Ferguson, Structures of glycosylphosphatidylinositol membrane anchors from Saccharomyces cerevisiae, J. Biol. Chem. 268 (1993) 26365-26374.

[9] I. Imhof, I. Flury, C. Vionnet, C. Roubaty, D. Egger, A. Conzelmann, Glycosylphosphatidylinositol (GPI) proteins of Saccharomyces cerevisiae contain ethanolamine phosphate groups on the alpha1,4-linked mannose of the GPI anchor, J. Biol. Chem. 279 (2004) 19614-19627.

[10] M.A. Ferguson, J.S. Brimacombe, J.R. Brown, A. Crossman, A. Dix, R.A. Field, M.L. Guther, K.G. Milne, D.K. Sharma, T.K. Smith, The GPI biosynthetic pathway as a therapeutic target for African sleeping sickness, Biochim. Biophys. Acta 1455 (1999) 327-340.

[11] M.A. Ferguson, The structure, biosynthesis and functions of glycosylphosphatidylinositol anchors, and the contributions of trypanosome research, J. Cell Sci. 112 (1999) 2799-2809.
[12] M. A. J. Ferguson, T. Kinoshita, G.W. Hart, Glycophospholipid anchors, in: A. Varki, C, Bertozzi, R. Cummings, M. Etzler, J. Esko, H. Freeze, G. Hart, P. Stanley (Eds.), Essential Glycobiology, 2nd ed. (in press).

[13] B. Eisenhaber, S. Maurer-Stroh, M. Novatchkova, G. Schneider, F. Eisenhaber, Enzymes and auxiliary factors for GPI lipid anchor biosynthesis and post-translational transfer to proteins, BioEssays 25 (2003) 367-385.

[14] H. Ikezawa, Glycosylphosphatidylinositol (GPI)-anchored proteins, Biol. Pharm. Bull. 25 (2002) 409-417.

[15] M.J. McConville, A.K. Menon, Recent developments in the cell biology and biochemistry of glycosylphosphatidylinositol lipids (review), Mol. Membr. Biol. 17 (2000) 1-16.

[16] M.P. Schreuder, S. Brekelmans, H. van den Ende, F.M. Klis, Targeting of a heterologous protein to the cell wall of Saccharomyces cerevisiae, Yeast 9 (1993) 399-409.

[17] C.F. Lu, R.C. Montijn, J.L. Brown, F. Klis, J. Kurjan, H. Bussey, P.N. Lipke, Glycosyl phosphatidylinositol-dependent cross-linking of alphaagglutinin and beta 1,6-glucan in the Saccharomyces cerevisiae cell wall, J. Cell Biol. 128 (1995) 333-340.

[18] J.M. Van der Vaart, R. te Biesebeke, J.W. Chapman, H.Y. Toschka, F.M. Klis, C.T. Verrips, Comparison of cell wall proteins of Saccharomyces cerevisiae as anchors for cell surface expression of heterologous proteins, Appl. Environ. Microbiol. 63 (1997) 615-620.

[19] B. Jiang, J. Sheraton, A.F. Ram, G.J. Dijkgraaf, F.M. Klis, H. Bussey, CWH41 encodes a novel endoplasmic reticulum membrane N-glycoprotein involved in beta 1,6-glucan assembly, J. Bacteriol. 178 (1996) $1162-1171$

[20] K. Machi, M. Azuma, K. Igarashi, T. Matsumoto, H. Fukuda, A. Kondo, H. Ooshima, Rotlp of Saccharomyces cerevisiae is a putative membrane protein required for normal levels of the cell wall 1,6-beta-glucan, Microbiology 150 (2004) 3163-3173.

[21] J.C. Kapteyn, P. van Egmond, E. Sievi, H. van den Ende, M. Makarow, F.M. Klis, The contribution of the O-glycosylated protein Pir2p/Hsp150 to the construction of the yeast cell wall in wild-type cells and beta 1,6glucan-deficient mutants, Mol. Microbiol. 31 (1999) 1835-1844.

[22] J.C. Kapteyn, R.C. Montijn, E. Vink, J. de la Cruz, A. Llobell, J.E. Douwes, H. Shimoi, P.N. Lipke, F.M. Klis, Retention of Saccharomyces cerevisiae cell wall proteins through a phosphodiester-linked beta-1,3-/ beta-1,6-glucan heteropolymer, Glycobiology 6 (1996) 337-345.

[23] P.W.J. De Groot, A.F. Ram, F.M. Klis, Features and functions of covalently linked proteins in fungal cell walls, Fungal Genet. Biol. 42 (2005) 657-675.

[24] P. Orlean, Biogenesis of yeast wall and surface components, in: J. Pringle, J. Broach, E. Jones (Eds.), The Molecular and Cellular Biology of the Yeast Saccharomyces, Cold Spring Harbor Laboratory Press, 1997, pp. 229-362.

[25] S. Shahinian, H. Bussey, beta-1,6-Glucan synthesis in Saccharomyces cerevisiae, Mol. Microbiol. 35 (2000) 477-489.

[26] H. de Nobel, H. van den Ende, F.M. Klis, Cell wall maintenance in fungi, Trends Microbiol. 8 (2000) 344-345.

[27] G.J. Smits, H. van den Ende, F.M. Klis, Differential regulation of cell wall biogenesis during growth and development in yeast, Microbiology 147 (2001) 781-794.

[28] F.M. Klis, P. Mol, K. Hellingwerf, S. Brul, Dynamics of cell wall structure in Saccharomyces cerevisiae, FEMS Microbiol. Rev 26 (2002) 239-256.

[29] L.H. Caro, H. Tettelin, J.H. Vossen, A.F. Ram, H. van den Ende, F.M. Klis, In silicio identification of glycosyl-phosphatidylinositol-anchored plasma-membrane and cell wall proteins of Saccharomyces cerevisiae, Yeast 13 (1997) 1477-1489.

[30] P.W. De Groot, K.J. Hellingwerf, F.M. Klis, Genome-wide identification of fungal GPI proteins, Yeast 20 (2003) 781-796.

[31] K. Hamada, S. Fukuchi, M. Arisawa, M. Baba, K. Kitada, Screening for glycosylphosphatidylinositol (GPI)-dependent cell wall proteins in Saccharomyces cerevisiae, Mol. Gen. Genet. 258 (1998) 53-59.

[32] Q.Y. Yin, P.W. de Groot, H.L. Dekker, L. de Jong, F.M. Klis, C.G. de Koster, Comprehensive proteomic analysis of Saccharomyces cerevisiae cell walls: identification of proteins covalently attached via glycosylphosphatidylinositol remnants or mild alkali-sensitive linkages, J. Biol. Chem. 280 (2005) 20894-20901. 
[33] S.D. Leidich, Z. Kostova, R.R. Latek, L.C. Costello, D.A. Drapp, W. Gray, J.S. Fassler, P. Orlean, Temperature-sensitive yeast GPI anchoring mutants gpi2 and gpi3 are defective in the synthesis of N-acetylglucosaminyl phosphatidylinositol. Cloning of the GPI2 gene, J. Biol. Chem. 270 (1995) 13029-13035.

[34] B.C. Yan, B.A. Westfall, P. Orlean, Ynl038wp (Gpi15p) is the Saccharomyces cerevisiae homologue of human Pig- $\mathrm{Hp}$ and participates in the first step in glycosylphosphatidylinositol assembly, Yeast 18 (2001) $1383-1389$

[35] H.A. Newman, M.J. Romeo, S.E. Lewis, B.C. Yan, P. Orlean, D.E. Levin, Gpi19, the Saccharomyces cerevisiae homologue of mammalian PIG-P, is a subunit of the initial enzyme for glycosylphosphatidylinositol anchor biosynthesis, Eukaryot. Cell 4 (2005) 1801-1807.

[36] Z. Kostova, D.M. Rancour, A.K. Menon, P. Orlean, Photoaffinity labelling with P3-(4-azidoanilido)uridine 5'-triphosphate identifies gpi3p as the UDP-GlcNAc-binding subunit of the enzyme that catalyses formation of GlcNAc-phosphatidylinositol, the first glycolipid intermediate in glycosylphosphatidylinositol synthesis, Biochem. J. 3 (2000) $815-822$.

[37] Y. Hong, K. Ohishi, R. Watanabe, Y. Endo, Y. Maeda, T. Kinoshita, GPI1 stabilizes an enzyme essential in the first step of glycosylphosphatidylinositol biosynthesis, J. Biol. Chem. 274 (1999) 18582-18588.

[38] R. Watanabe, Y. Murakami, M.D. Marmor, N. Inoue, Y. Maeda, J. Hino, K. Kangawa, M. Julius, T. Kinoshita, Initial enzyme for glycosylphosphatidylinositol biosynthesis requires PIG-P and is regulated by DPM2, EMBO J. 19 (2000) 4402-4411.

[39] P.A. Colussi, C.H. Taron, J.C. Mack, P. Orlean, Human and Saccharomyces cerevisiae dolichol phosphate mannose synthases represent two classes of the enzyme, but both function in Schizosaccharomyces pombe, Proc. Natl. Acad. Sci. U. S. A. 94 (1997) 7873-7878.

[40] A.K. Sobering, R. Watanabe, M.J. Romeo, B.C. Yan, C.A. Specht, P. Orlean, H. Riezman, D.E. Levin, Yeast Ras regulates the complex that catalyzes the first step in GPI-anchor biosynthesis at the ER, Cell 117 (2004) 637-648.

[41] Y. Murakami, U. Siripanyaphinyo, Y. Hong, Y. Tashima, Y. Maeda, T. Kinoshita, The initial enzyme for glycosylphosphatidylinositol biosynthesis requires PIG-Y, a seventh component, Mol. Biol. Cell 16 (2005) 5236-5246.

[42] J.H. Chi, J. Roos, N. Dean, The OST4 gene of Saccharomyces cerevisiae encodes an unusually small protein required for normal levels of oligosaccharyltransferase activity, J. Biol. Chem. 271 (1996) 3132-3140.

[43] W.L. Roberts, J.J. Myher, A. Kuksis, M.G. Low, T.L. Rosenberry, Lipid analysis of the glycoinositol phospholipid membrane anchor of human erythrocyte acetylcholinesterase. Palmitoylation of inositol results in resistance to phosphatidylinositol-specific phospholipase C, J. Biol. Chem. 263 (1988) 18766-18775.

[44] W.L. Roberts, S. Santikarn, V.N. Reinhold, T.L. Rosenberry, Structural characterization of the glycoinositol phospholipid membrane anchor of human erythrocyte acetylcholinesterase by fast atom bombardment mass spectrometry, J. Biol. Chem. 263 (1988) 18776-18784.

[45] R. Chen, E.I. Walter, G. Parker, J.P. Lapurga, J.L. Millan, Y. Ikehara, S. Udenfriend, M.E. Medof, Mammalian glycophosphatidylinositol anchor transfer to proteins and posttransfer deacylation, Proc. Natl. Acad. Sci. U. S. A. 95 (1998) 9512-9517.

[46] N. Singh, D. Singleton, A.M. Tartakoff, Anchoring and degradation of glycolipid-anchored membrane proteins by L929 versus by LM-TKmouse fibroblasts: implications for anchor biosynthesis, Mol. Cell. Biol. 11 (1991) 2362-2374.

[47] P. Gerold, L. Schofield, M.J. Blackman, A.A. Holder, R.T. Schwarz, Structural analysis of the glycosyl-phosphatidylinositol membrane anchor of the merozoite surface proteins-1 and-2 of Plasmodium falciparum, Mol. Biochem. Parasitol. 75 (1996) 131-143.

[48] S. Tanaka, Y. Maeda, Y. Tashima, T. Kinoshita, Inositol deacylation of glycosylphosphatidylinositol-anchored proteins is mediated by mammalian PGAP1 and yeast Bst1p, J. Biol. Chem. 279 (2004) 14256-14263.

[49] G. Sipos, F. Reggiori, C. Vionnet, A. Conzelmann, Alternative lipid remodelling pathways for glycosylphosphatidylinositol membrane anchors in Saccharomyces cerevisiae, EMBO J. 16 (1997) 3494-3505.
[50] L.C. Costello, P. Orlean, Inositol acylation of a potential glycosyl phosphoinositol anchor precursor from yeast requires acyl coenzyme A, J. Biol. Chem. 267 (1992) 8599-8603.

[51] W.T. Doerrler, J. Ye, J.R. Falck, M.A. Lehrman, Acylation of glucosaminyl phosphatidylinositol revisited. Palmitoyl-CoA dependent palmitoylation of the inositol residue of a synthetic dioctanoyl glucosaminyl phosphatidylinositol by hamster membranes permits efficient mannosylation of the glucosamine residue, J. Biol. Chem. 271 (1996) 27031-27038.

[52] H. Shimoi, K. Sakamoto, M. Okuda, R. Atthi, K. Iwashita, K. Ito, The Awal gene is required for the foam-forming phenotype and cell surface hydrophobicity of sake yeast, Appl. Environ. Microbiol. 68 (2002) 2018-2025.

[53] Y. Murakami, U. Siripanyapinyo, Y. Hong, J.Y. Kang, S. Ishihara, H. Nakakuma, Y. Maeda, T. Kinoshita, PIG-W is critical for inositol acylation but not for flipping of glycosylphosphatidylinositol-anchor, Mol. Biol. Cell 14 (2003) 4285-4295.

[54] Y. Maeda, R. Watanabe, C.L. Harris, Y. Hong, K. Ohishi, K. Kinoshita, T. Kinoshita, PIG-M transfers the first mannose to glycosylphosphatidylinositol on the lumenal side of the ER, EMBO J. 20 (2001) 250-261.

[55] H. Ashida, Y. Hong, Y. Murakami, N. Shishioh, N. Sugimoto, Y.U. Kim, Y. Maeda, T. Kinoshita, Mammalian PIG-X and yeast Pbnlp are the essential components of glycosylphosphatidylinositol-mannosyltransferase I, Mol. Biol. Cell (2005)

[56] R.R. Naik, E.W. Jones, The PBN1 gene of Saccharomyces cerevisiae: an essential gene that is required for the post-translational processing of the protease B precursor, Genetics 149 (1998) 1277-1292.

[57] J.Y. Kang, Y. Hong, H. Ashida, N. Shishioh, Y. Murakami, Y.S. Morita, Y. Maeda, T. Kinoshita, PIG-V involved in transferring the second mannose in glycosylphosphatidylinositol, J. Biol. Chem. 280 (2005) 9489-9497.

[58] E.C. Gaynor, G. Mondesert, S.J. Grimme, S.I. Reed, P. Orlean, S.D. Emr, MCD4 encodes a conserved endoplasmic reticulum membrane protein essential for glycosylphosphatidylinositol anchor synthesis in yeast, Mol. Biol. Cell 10 (1999) 627-648.

[59] Y. Hong, Y. Maeda, R. Watanabe, K. Ohishi, M. Mishkind, H. Riezman, T. Kinoshita, Pig-n, a mammalian homologue of yeast Mcd4p, is involved in transferring phosphoethanolamine to the first mannose of the glycosylphosphatidylinositol, J. Biol. Chem. 274 (1999) 35099-35106.

[60] I. Imhof, E. Canivenc-Gansel, U. Meyer, A. Conzelmann, Phosphatidylethanolamine is the donor of the phosphorylethanolamine linked to the alpha1,4-linked mannose of yeast GPI structures, Glycobiology 10 (2000) 1271-1275.

[61] C. Sutterlin, A. Horvath, P. Gerold, R.T. Schwarz, Y. Wang, M. Dreyfuss, H. Riezman, Identification of a species-specific inhibitor of glycosylphosphatidylinositol synthesis, EMBO J. 16 (1997) 6374-6383.

[62] C. Sutterlin, M.V. Escribano, P. Gerold, Y. Maeda, M.J. Mazon, T. Kinoshita, R.T. Schwarz, H. Riezman, Saccharomyces cerevisiae GPI10, the functional homologue of human PIG-B, is required for glycosylphosphatidylinositolanchor synthesis, Biochem. J. 332 (1998) 153-159.

[63] M.K. Storey, W.I. Wu, D.R. Voelker, A genetic screen for ethanolamine auxotrophs in Saccharomyces cerevisiae identifies a novel mutation in Mcd4p, a protein implicated in glycosylphosphatidylinositol anchor synthesis, Biochim. Biophys. Acta 1532 (2001) 234-247.

[64] A. Toh-e, T. Oguchi, Genetic characterization of genes encoding enzymes catalyzing addition of phospho-ethanolamine to the glycosylphosphatidylinositol anchor in Saccharomyces cerevisiae, Genes Genet. Syst. 77 (2002) 309-322.

[65] Y. Zhu, C. Vionnet, A. Conzelmann, Ethanolaminephosphate side chain added to GPI anchor by Mcd $4 p$ is required for ceramide remodeling and forward transport of GPI proteins from ER to Golgi, J. Biol. Chem. (2006).

[66] I. Flury, A. Benachour, A. Conzelmann, YLL031c belongs to a novel family of membrane proteins involved in the transfer of ethanolaminephosphate onto the core structure of glycosylphosphatidylinositol anchors in yeast, J. Biol. Chem. 275 (2000) 24458-24465.

[67] Y. Hong, Y. Maeda, R. Watanabe, N. Inoue, K. Ohishi, T. Kinoshita, Requirement of PIG-F and PIG-O for transferring phosphoethanolamine 
to the third mannose in glycosylphosphatidylinositol, J. Biol. Chem. 275 (2000) 20911-20919.

[68] S.J. Grimme, B.A. Westfall, J.M. Wiedman, C.H. Taron, P. Orlean, The essential Smp3 protein is required for addition of the side-branching fourth mannose during assembly of yeast glycosylphosphatidylinositols, J. Biol. Chem. 276 (2001) 27731-27739.

[69] S.J. Grimme, P.A. Colussi, C.H. Taron, P. Orlean, Deficiencies in the essential Smp3 mannosyltransferase block glycosylphosphatidylinositol assembly and lead to defects in growth and cell wall biogenesis in Candida albicans, Microbiology 150 (2004) 3115-3128.

[70] B.W. Taron, P.A. Colussi, J.M. Wiedman, P. Orlean, C.H. Taron, Human Smp3p adds a fourth mannose to yeast and human glycosylphosphatidylinositol precursors in vivo, J. Biol. Chem. 279 (2004) 36083-36092.

[71] A. Benachour, G. Sipos, I. Flury, F. Reggiori, E. Canivenc-Gansel, C. Vionnet, A. Conzelmann, M. Benghezal, Deletion of GPI7, a yeast gene required for addition of a side chain to the glycosylphosphatidylinositol (GPI) core structure, affects GPI protein transport, remodeling, and cell wall integrity, J. Biol. Chem. 274 (1999) 15251-15261.

[72] C.H. Taron, J.M. Wiedman, S.J. Grimme, P. Orlean, Glycosylphosphatidylinositol biosynthesis defects in Gpil1p- and Gpi13p-deficient yeast suggest a branched pathway and implicate gpi13p in phosphoethanolamine transfer to the third mannose, Mol. Biol. Cell 11 (2000) $1611-1630$.

[73] N. Shishioh, Y. Hong, K. Ohishi, H. Ashida, Y. Maeda, T. Kinoshita, GPI7 is the second partner of PIG-F and involved in modification of glycosylphosphatidylinositol, J. Biol. Chem. (2005).

[74] M. Fujita, T. Yoko-O, M. Okamoto, Y. Jigami, GPI7 involved in glycosylphosphatidylinositol biosynthesis is essential for yeast cell separation, J. Biol. Chem. 279 (2004) 51869-51879.

[75] W.K. Huh, J.V. Falvo, L.C. Gerke, A.S. Carroll, R.W. Howson, J.S. Weissman, E.K. O'Shea, Global analysis of protein localization in budding yeast, Nature 425 (2003) 686-691.

[76] M. Benghezal, P.N. Lipke, A. Conzelmann, Identification of six complementation classes involved in the biosynthesis of glycosylphosphatidylinositol anchors in Saccharomyces cerevisiae, J. Cell Biol. 130 (1995) 1333-1344.

[77] K. Yusa, K. Horie, G. Kondoh, M. Kouno, Y. Maeda, T. Kinoshita, J. Takeda, Genome-wide phenotype analysis in ES cells by regulated disruption of Bloom's syndrome gene, Nature 429 (2004) 896-899.

[78] D. Hamburger, M. Egerton, H. Riezman, Yeast Gaalp is required for attachment of a completed GPI anchor onto proteins, J. Cell Biol. 129 (1995) 629-639.

[79] M. Benghezal, A. Benachour, S. Rusconi, M. Aebi, A. Conzelmann, Yeast Gpi8p is essential for GPI anchor attachment onto proteins, EMBO J. 15 (1996) 6575-6583.

[80] P. Fraering, I. Imhof, U. Meyer, J.M. Strub, A. van Dorsselaer, C. Vionnet, A. Conzelmann, The GPI transamidase complex of Saccharomyces cerevisiae contains Gaalp, Gpi8p, and Gpi16p, Mol. Biol. Cell 12 (2001) 3295-3306.

[81] K. Ohishi, N. Inoue, T. Kinoshita, PIG-S and PIG-T, essential for GPI anchor attachment to proteins, form a complex with GAA1 and GPI8, EMBO J. 20 (2001) 4088-4098.

[82] Y. Hong, K. Ohishi, J.Y. Kang, S. Tanaka, N. Inoue, J. Nishimura, Y. Maeda, T. Kinoshita, Human PIG-U and yeast Cdc91p are the fifth subunit of GPI transamidase that attaches GPI-anchors to proteins, Mol. Biol. Cell 14 (2003) 1780-1789.

[83] U. Meyer, M. Benghezal, I. Imhof, A. Conzelmann, Active site determination of Gpi8p, a caspase-related enzyme required for glycosylphosphatidylinositol anchor addition to proteins, Biochemistry 39 (2000) 3461-3471.

[84] K. Ohishi, N. Inoue, Y. Maeda, J. Takeda, H. Riezman, T. Kinoshita, Gaalp and Gpi8p are components of a glycosylphosphatidylinositol (GPI) transamidase that mediates attachment of GPI to proteins, Mol. Biol. Cell 11 (2000) 1523-1533.

[85] X. Kang, A. Szallies, M. Rawer, H. Echner, M. Duszenko, GPI anchor transamidase of Trypanosoma brucei: in vitro assay of the recombinant protein and VSG anchor exchange, J. Cell Sci. 115 (2002) 2529-2539.

[86] K. Ohishi, K. Nagamune, Y. Maeda, T. Kinoshita, Two subunits of glyco- sylphosphatidylinositol transamidase, GPI8 and PIG-T, form a functionally important intermolecular disulfide bridge, J. Biol. Chem. 278 (2003) 13959-13967.

[87] Y. Hong, K. Nagamune, K. Ohishi, Y.S. Morita, H. Ashida, Y. Maeda, T. Kinoshita, TbGPI16 is an essential component of GPI transamidase in Trypanosoma brucei, FEBS Lett. 580 (2006) 603-606.

[88] S. Vainauskas, Y. Maeda, H. Kurniawan, T. Kinoshita, A.K. Menon, Structural requirements for the recruitment of Gaal into a functional glycosylphosphatidylinositol transamidase complex, J. Biol. Chem. 277 (2002) 30535-30542.

[89] S. Vainauskas, A.K. Menon, A conserved proline in the last transmembrane segment of Gaal is required for glycosylphosphatidylinositol (GPI) recognition by GPI transamidase, J. Biol. Chem. 279 (2004) 6540-6545.

[90] S.J. Grimme, X.D. Gao, P.S. Martin, K. Tu, S.E. Tcheperegine, K. Corrado, A.E. Farewell, P. Orlean, E. Bi, Deficiencies in the endoplasmic reticulum (ER)-membrane protein Gablp perturb transfer of glycosylphosphatidylinositol to proteins and cause perinuclear ER-associated actin bar formation, Mol. Biol. Cell 15 (2004) 2758-2770.

[91] K. Nagamune, K. Ohishi, H. Ashida, Y. Hong, J. Hino, K. Kangawa, N. Inoue, Y. Maeda, T. Kinoshita, GPI transamidase of Trypanosoma brucei has two previously uncharacterized (trypanosomatid transamidase 1 and 2) and three common subunits, Proc. Natl. Acad. Sci. U. S. A. 100 (2003) $10682-10687$.

[92] S. Ghaemmaghami, W.K. Huh, K. Bower, R.W. Howson, A. Belle, N. Dephoure, E.K. O'Shea, J.S. Weissman, Global analysis of protein expression in yeast, Nature 425 (2003) 737-741.

[93] A. Conzelmann, Biosynthesis, remodeling and targeting of GPI proteins in the yeast Saccharomyces cerevisiae, in: G. Daum (Ed.), Cell Biology and Dynamics of Yeast Lipids, Research Signpost, Trivandrum, Kerala, India, 2005, pp. 133-159.

[94] Y. Zhu, P. Fraering, C. Vionnet, A. Conzelmann, Gpi17p does not stably interact with other subunits of glycosylphosphatidylinositol transamidase in Saccharomyces cerevisiae, Biochim. Biophys. Acta 1735 (2005) 79-88.

[95] M. Umemura, M. Okamoto, K. Nakayama, K. Sagane, K. Tsukahara, K. Hata, Y. Jigami, GWT1 gene is required for inositol acylation of glycosylphosphatidylinositol anchors in yeast, J. Biol. Chem. 278 (2003) 23639-23647.

[96] S. Vashist, W. Kim, W.J. Belden, E.D. Spear, C. Barlowe, D.T. Ng, Distinct retrieval and retention mechanisms are required for the quality control of endoplasmic reticulum protein folding, J. Cell Biol. 155 (2001) 355-368.

[97] S. Vashist, D.T. Ng, Misfolded proteins are sorted by a sequential checkpoint mechanism of ER quality control, J. Cell Biol. 165 (2004) $41-52$.

[98] M. Fujita, T. Yoko-O, Y. Jigami, Inositol deacylation by Bst1p is required for the quality control of glycosylphosphatidylinositol-anchored proteins, Mol. Biol. Cell 17 (2006) 834-850.

[99] J.E. Ralton, K.A. Mullin, M.J. McConville, Intracellular trafficking of glycosylphosphatidylinositol (GPI)-anchored proteins and free GPIs in Leishmania mexicana, Biochem. J. 363 (2002) 365-375.

[100] N.A. Baumann, J. Vidugiriene, C.E. Machamer, A.K. Menon, Cell surface display and intracellular trafficking of free glycosylphosphatidylinositols in mammalian cells, J. Biol. Chem. 275 (2000) 7378-7389.

[101] N. Singh, L.N. Liang, M.L. Tykocinski, A.M. Tartakoff, A novel class of cell surface glycolipids of mammalian cells. Free glycosyl phosphatidylinositols, J. Biol. Chem. 271 (1996) 12879-12884.

[102] A. Puoti, A. Conzelmann, Structural characterization of free glycolipids which are potential precursors for glycophosphatidylinositol anchors in mouse thymoma cell lines, J. Biol. Chem. 267 (1992) 22673-22680.

[103] R. Schneiter, B. Brugger, C.M. Amann, G.D. Prestwich, R.F. Epand, G. Zellnig, F.T. Wieland, R.M. Epand, Identification and biophysical characterization of a very-long-chain-fatty-acid-substituted phosphatidylinositol in yeast subcellular membranes, Biochem. J. 381 (2004) 941-949.

[104] T. Fontaine, T. Magnin, A. Melhert, D. Lamont, J.P. Latge, M.A. Ferguson, Structures of the glycosylphosphatidylinositol membrane anchors from Aspergillus fumigatus membrane proteins, Glycobiology 13 (2003) 169-177. 
[105] L.E. Bertello, M.J. Alves, W. Colli, R.M. de Lederkremer, Inositolphosphoceramide is not a substrate for the first steps in the biosynthesis of glycoinositolphospholipids in Trypanosoma cruzi, Mol. Biochem. Parasitol. 133 (2004) 71-80.

[106] F. Reggiori, E. Canivenc-Gansel, A. Conzelmann, Lipid remodeling leads to the introduction and exchange of defined ceramides on GPI proteins in the ER and Golgi of Saccharomyces cerevisiae, EMBO J. 16 (1997) 3506-3518.

[107] F. Reggiori, A. Conzelmann, Biosynthesis of inositol phosphoceramides and remodeling of glycosylphosphatidylinositol anchors in Saccharomyces cerevisiae are mediated by different enzymes, J. Biol. Chem. 273 (1998) 30550-30559.

[108] R. Bosson, M. Jaquenoud, A. Conzelmann, GUP1 of Saccharomyces cerevisiae encodes an O-acyltransferase involved in remodeling of the GPI anchor, Mol. Biol. Cell (2006).

[109] Y. Tashima, R. Taguchi, C. Murata, H. Ashida, T. Kinoshita, Y. Maeda, PGAP2 is essential for correct processing and stable expression of GPIanchored proteins, Mol. Biol. Cell 17 (2006) 1410-1420.

[110] H. Martin-Yken, A. Dagkessamanskaia, P. De Groot, A. Ram, F. Klis, J. Francois, Saccharomyces cerevisiae YCRO17c/CWH43 encodes a putative sensor/transporter protein upstream of the BCK2 branch of the PKC1-dependent cell wall integrity pathway, Yeast 18 (2001) 827-840.

[111] G. Sipos, A. Puoti, A. Conzelmann, Biosynthesis of the side chain of yeast glycosylphosphatidylinositol anchors is operated by novel mannosyltransferases located in the endoplasmic reticulum and the Golgi apparatus, J. Biol. Chem. 270 (1995) 19709-19715.

[112] M. Lussier, A.M. Sdicu, H. Bussey, The KTR and MNN1 mannosyltransferase families of Saccharomyces cerevisiae, Biochim. Biophys. Acta 1426 (1999) 323-334.

[113] T.L. Doering, R. Schekman, GPI anchor attachment is required for Gas $1 p$ transport from the endoplasmic reticulum in COP II vesicles, EMBO J. 15 (1996) 182-191.

[114] M.D. Delahunty, F.J. Stafford, L.C. Yuan, D. Shaz, J.S. Bonifacino, Uncleaved signals for glycosylphosphatidylinositol anchoring cause retention of precursor proteins in the endoplasmic reticulum, J. Biol. Chem. 268 (1993) 12017-12027.

[115] F. Letourneur, P. Cosson, Targeting to the endoplasmic reticulum in yeast cells by determinants present in transmembrane domains, J. Biol. Chem. 273 (1998) 33273-33278.

[116] A. Horvath, C. Sutterlin, U. Manning-Krieg, N.R. Movva, H. Riezman, Ceramide synthesis enhances transport of GPI-anchored proteins to the Golgi apparatus in yeast, EMBO J. 13 (1994) 3687-3695.

[117] C. Sutterlin, T.L. Doering, F. Schimmoller, S. Schroder, H. Riezman, Specific requirements for the ER to Golgi transport of GPI-anchored proteins in yeast, J. Cell Sci. 110 (1997) 2703-2714.

[118] M. Skrzypek, R.L. Lester, R.C. Dickson, Suppressor gene analysis reveals an essential role for sphingolipids in transport of glycosylphosphatidylinositol-anchored proteins in Saccharomyces cerevisiae, J. Bacteriol. 179 (1997) 1513-1520.

[119] W.P. Barz, P. Walter, Two endoplasmic reticulum (ER) membrane proteins that facilitate ER-to-Golgi transport of glycosylphosphatidylinositol-anchored proteins, Mol. Biol. Cell 10 (1999) 1043-1059.

[120] M. Marzioch, D.C. Henthorn, J.M. Herrmann, R. Wilson, D.Y. Thomas, J.J. Bergeron, R.C. Solari, A. Rowley, Erp1p and Erp2p, partners for Emp24p and Erv25p in a yeast p24 complex, Mol. Biol. Cell 10 (1999) 1923-1938.

[121] R. Watanabe, K. Funato, K. Venkataraman, A.H. Futerman, H. Riezman, Sphingolipids are required for the stable membrane association of glycosylphosphatidylinositol-anchored proteins in yeast, J. Biol. Chem. 277 (2002) 49538-49544.

[122] M. Muniz, C. Nuoffer, H.P. Hauri, H. Riezman, The Emp24 complex recruits a specific cargo molecule into endoplasmic reticulum-derived vesicles, J. Cell Biol. 148 (2000) 925-930.

[123] E. Friedmann, Y. Salzberg, A. Weinberger, S. Shaltiel, J.E. Gerst, YOS9, the putative yeast homolog of a gene amplified in osteosarcomas, is involved in the endoplasmic reticulum (ER)-Golgi transport of GPIanchored proteins, J. Biol. Chem. 277 (2002) 35274-35281.

[124] R. Szathmary, R. Bielmann, M. Nita-Lazar, P. Burda, C.A. Jakob, Yos9 protein is essential for degradation of misfolded glycoproteins and may function as lectin in ERAD, Mol. Cell 19 (2005) 765-775.

[125] W. Kim, E.D. Spear, D.T. Ng, Yos9p detects and targets misfolded glycoproteins for ER-associated degradation, Mol. Cell 19 (2005) 753-764.

[126] A. Bhamidipati, V. Denic, E.M. Quan, J.S. Weissman, Exploration of the topological requirements of ERAD identifies Yos9p as a lectin sensor of misfolded glycoproteins in the ER lumen, Mol. Cell 19 (2005) 741-751.

[127] M. Muniz, P. Morsomme, H. Riezman, Protein sorting upon exit from the endoplasmic reticulum, Cell 104 (2001) 313-320.

[128] P. Morsomme, H. Riezman, The Rab GTPase Yptlp and tethering factors couple protein sorting at the ER to vesicle targeting to the Golgi apparatus, Dev. Cell 2 (2002) 307-317.

[129] E. Harsay, A. Bretscher, Parallel secretory pathways to the cell surface in yeast, J. Cell Biol. 131 (1995) 297-310.

[130] D. David, S. Sundarababu, J.E. Gerst, Involvement of long chain fatty acid elongation in the trafficking of secretory vesicles in yeast, J. Cell Biol. 143 (1998) 1167-1182.

[131] S. Gurunathan, D. David, J.E. Gerst, Dynamin and clathrin are required for the biogenesis of a distinct class of secretory vesicles in yeast, EMBO J. 21 (2002) 602-614.

[132] Q. Lisman, T. Pomorski, C. Vogelzangs, D. Urli-Stam, W. de Cocq van Delwijnen, J.C. Holthuis, Protein sorting in the late Golgi of Saccharomyces cerevisiae does not require mannosylated sphingolipids, J. Biol. Chem. 279 (2004) 1020-1029.

[133] E. Sievi, T. Suntio, M. Makarow, Proteolytic function of GPI-anchored plasma membrane protease Ypslp in the yeast vacuole and Golgi, Traffic 2 (2001) 896-907.

[134] J.M. Rodriguez-Pena, C. Rodriguez, A. Alvarez, C. Nombela, J. Arroyo, Mechanisms for targeting of the Saccharomyces cerevisiae GPI-anchored cell wall protein Crh2p to polarised growth sites, J. Cell Sci. 115 (2002) 2549-2558.

[135] V. Baladron, S. Ufano, E. Duenas, A.B. Martin-Cuadrado, F. del Rey, C.R. Vazquez de Aldana, Eng1p, an endo-1,3-beta-glucanase localized at the daughter side of the septum, is involved in cell separation in Saccharomyces cerevisiae, Eukaryot. Cell 1 (2002) 774-786.

[136] B. Kovacech, K. Nasmyth, T. Schuster, EGT2 gene transcription is induced predominantly by Swi5 in early G1, Mol. Cell. Biol. 16 (1996) 3264-3274.

[137] A. Colman-Lerner, T.E. Chin, R. Brent, Yeast Cbk1 and Mob2 activate daughter-specific genetic programs to induce asymmetric cell fates, Cell 107 (2001) 739-750.

[138] S. Mayor, H. Riezman, Sorting GPI-anchored proteins, Nat. Rev., Mol. Cell Biol. 5 (2004) 110-120.

[139] J.C. Kapteyn, L.L. Hoyer, J.E. Hecht, W.H. Muller, A. Andel, A.J. Verkleij, M. Makarow, H. Van Den Ende, F.M. Klis, The cell wall architecture of Candida albicans wild-type cells and cell wall-defective mutants, Mol. Microbiol. 35 (2000) 601-611.

[140] M.B. Frieman, J.M. McCaffery, B.P. Cormack, Modular domain structure in the Candida glabrata adhesin Epa1p, a beta1,6 glucan-cross-linked cell wall protein, Mol. Microbiol. 46 (2002) 479-492.

[141] P.W. de Groot, A.D. de Boer, J. Cunningham, H.L. Dekker, L. de Jong, K.J. Hellingwerf, C. de Koster, F.M. Klis, Proteomic analysis of Candida albicans cell walls reveals covalently bound carbohydrate-active enzymes and adhesins, Eukaryot. Cell 3 (2004) 955-965.

[142] J.M. Bruneau, T. Magnin, E. Tagat, R. Legrand, M. Bernard, M. Diaquin, C. Fudali, J.P. Latge, Proteome analysis of Aspergillus fumigatus identifies glycosylphosphatidylinositol-anchored proteins associated to the cell wall biosynthesis, Electrophoresis 22 (2001) 2812-2823.

[143] J.P. Latge, I. Mouyna, F. Tekaia, A. Beauvais, J.P. Debeaupuis, W. Nierman, Specific molecular features in the organization and biosynthesis of the cell wall of Aspergillus fumigatus, Med. Mycol. 43 (Suppl. 1) (2005) S15-S22.

[144] R. Kollar, B.B. Reinhold, E. Petrakova, H.J. Yeh, G. Ashwell, J. Drgonova, J.C. Kapteyn, F.M. Klis, E. Cabib, Architecture of the yeast cell wall. $\operatorname{Beta}(1 \rightarrow 6)$-glucan interconnects mannoprotein, $\operatorname{beta}(1 \rightarrow) 3$ glucan, and chitin, J. Biol. Chem. 272 (1997) 17762-17775.

[145] J.H. Vossen, W.H. Muller, P.N. Lipke, F.M. Klis, Restrictive glycosylphosphatidylinositol anchor synthesis in cwh6/gpi3 yeast cells causes aberrant biogenesis of cell wall proteins, J. Bacteriol. 179 (1997) 2202-2209. 
[146] K. Hamada, H. Terashima, M. Arisawa, N. Yabuki, K. Kitada, Amino acid residues in the omega-minus region participate in cellular localization of yeast glycosylphosphatidylinositol-attached proteins, J. Bacteriol. 181 (1999) 3886-3889.

[147] M.B. Frieman, B.P. Cormack, The omega-site sequence of glycosylphosphatidylinositol-anchored proteins in Saccharomyces cerevisiae can determine distribution between the membrane and the cell wall, Mol. Microbiol. 50 (2003) 883-896.

[148] M.B. Frieman, B.P. Cormack, Multiple sequence signals determine the distribution of glycosylphosphatidylinositol proteins between the plasma membrane and cell wall in Saccharomyces cerevisiae, MicroBiology 150 (2004) 3105-3114.

[149] G. De Sampaio, J.P. Bourdineaud, G.J. Lauquin, A constitutive role for GPI anchors in Saccharomyces cerevisiae: cell wall targeting, Mol. Microbiol. 34 (1999) 247-256.

[150] H. Kitagaki, H. Wu, H. Shimoi, K. Ito, Two homologous genes, DCW1 (YKL046c) and DFG5, are essential for cell growth and encode glycosylphosphatidylinositol (GPI)-anchored membrane proteins required for cell wall biogenesis in Saccharomyces cerevisiae, Mol. Microbiol. 46 (2002) 1011-1022.

[151] H. Kitagaki, K. Ito, H. Shimoi, A temperature-sensitive dcw1 mutant of Saccharomyces cerevisiae is cell cycle arrested with small buds which have aberrant cell walls, Eukaryot. Cell 3 (2004) 1297-1306.

[152] A. Kondo, M. Ueda, Yeast cell-surface display-applications of molecular display, Appl. Microbiol. Biotechnol. 64 (2004) 28-40.

[153] S.D. Leidich, D.A. Drapp, P. Orlean, A conditionally lethal yeast mutant blocked at the first step in glycosyl phosphatidylinositol anchor synthesis, J. Biol. Chem. 269 (1994) 10193-10196.

[154] R. Teparic, I. Stuparevic, V. Mrsa, Increased mortality of Saccharomyces cerevisiae cell wall protein mutants, Microbiology 150 (2004) 3145-3150.

[155] I. Mouyna, T. Fontaine, M. Vai, M. Monod, W.A. Fonzi, M. Diaquin, L. Popolo, R.P. Hartland, J.P. Latge, Glycosylphosphatidylinositolanchored glucanosyltransferases play an active role in the biosynthesis of the fungal cell wall, J. Biol. Chem. 275 (2000) 14882-14889.

[156] C. Carotti, E. Ragni, O. Palomares, T. Fontaine, G. Tedeschi, R. Rodriguez, J.P. Latge, M. Vai, L. Popolo, Characterization of recombinant forms of the yeast Gas1 protein and identification of residues essential for glucanosyltransferase activity and folding, Eur. J. Biochem. 271 (2004) 3635-3645.
[157] H. Terashima, K. Hamada, K. Kitada, The localization change of Ybr078w/ Ecm33, a yeast GPI-associated protein, from the plasma membrane to the cell wall, affecting the cellular function, FEMS Microbiol. Lett. 218 (2003) $175-180$.

[158] D.T. Ng, J.D. Brown, P. Walter, Signal sequences specify the targeting route to the endoplasmic reticulum membrane, J. Cell Biol. 134 (1996) 269-278.

[159] L. Ni, M. Snyder, A genomic study of the bipolar bud site selection pattern in Saccharomyces cerevisiae, Mol. Biol. Cell 12 (2001) 2147-2170.

[160] S.D. Leidich, P. Orlean, Gpi1, a Saccharomyces cerevisiae protein that participates in the first step in glycosylphosphatidylinositol anchor synthesis, J. Biol. Chem. 271 (1996) 27829-27837.

[161] K.J. Travers, C.K. Patil, L. Wodicka, D.J. Lockhart, J.S. Weissman, P. Walter, Functional and genomic analyses reveal an essential coordination between the unfolded protein response and ER-associated degradation, Cell 101 (2000) 249-258.

[162] A.K. Sobering, M.J. Romeo, H.A. Vay, D.E. Levin, A novel Ras inhibitor, Eri1, engages yeast Ras at the endoplasmic reticulum, Mol. Cell. Biol. 23 (2003) 4983-4990.

[163] M.G. Lambrechts, F.F. Bauer, J. Marmur, I.S. Pretorius, Muc1, a mucinlike protein that is regulated by Mss10, is critical for pseudohyphal differentiation in yeast, Proc. Natl. Acad. Sci. U. S. A. 93 (1996) 8419-8424.

[164] L.S. Robertson, G.R. Fink, The three yeast A kinases have specific signaling functions in pseudohyphal growth, Proc. Natl. Acad. Sci. U. S. A. 95 (1998) $13783-13787$.

[165] J. Ash, M. Dominguez, J.J. Bergeron, D.Y. Thomas, Y. Bourbonnais, The yeast proprotein convertase encoded by YAP3 is a glycophosphatidylinositol-anchored protein that localizes to the plasma membrane, J. Biol. Chem. 270 (1995) 20847-20854.

[166] E. Canivenc-Gansel, I. Imhof, F. Reggiori, P. Burda, A. Conzelmann, A. Benachour, GPI anchor biosynthesis in yeast: phosphoethanolamine is attached to the alpha1,4-linked mannose of the complete precursor glycophospholipid, Glycobiology 8 (1998) 761-770.

[167] R. Watanabe, N. Inoue, B. Westfall, C.H. Taron, P. Orlean, J. Takeda, T. Kinoshita, The first step of glycosylphosphatidylinositol biosynthesis is mediated by a complex of PIG-A, PIG-H, PIG-C and GPI1, EMBO J. 17 (1998) 877-885. 